\title{
Surface characterization techniques for determining the root-mean-square roughness and power spectral densities of optical components
}

\author{
Angela Duparré, Josep Ferre-Borrull, Stefan Gliech, Gunther Notni, Jörg Steinert, and \\ Jean M. Bennett
}

\begin{abstract}
Surface topography and light scattering were measured on 15 samples ranging from those having smooth surfaces to others with ground surfaces. The measurement techniques included an atomic force microscope, mechanical and optical profilers, confocal laser scanning microscope, angle-resolved scattering, and total scattering. The samples included polished and ground fused silica, silicon carbide, sapphire, electroplated gold, and diamond-turned brass. The measurement instruments and techniques had different surface spatial wavelength band limits, so the measured roughnesses were not directly comparable. Two-dimensional power spectral density (PSD) functions were calculated from the digitized measurement data, and we obtained rms roughnesses by integrating areas under the PSD curves between fixed upper and lower band limits. In this way, roughnesses measured with different instruments and techniques could be directly compared. Although smaller differences between measurement techniques remained in the calculated roughnesses, these could be explained mostly by surface topographical features such as isolated particles that affected the instruments in different ways. (C) 2002 Optical Society of America
\end{abstract}

OCIS codes: $120.6660,180.1790,180.5810,240.5770,290.5820,290.5880$.

\section{Introduction}

For the past 15 years or so, there have been comparisons of measurements made on optical surfaces with different types of instruments and also comparisons of the performance of various types of instruments with respect to their upper and lower spatialfrequency bandwidth limits and the type of data produced. ${ }^{1}$ There have also been round-robin experiments to validate standards for effective rms roughness (by use of total integrated scattering), ,2,3 angle-resolved scattering (ARS), ${ }^{4-6}$ and total scattering (TS). ${ }^{7}$ In these latter measurements, nearly

When this research was performed, A. Duparré (duparre@iof.fhg.de), J. Ferre-Borrull, S. Gliech, G. Notni, and J. Steinert were with the Optical Systems Department, Fraunhofer Institute for Applied Optics and Precision Engineering, Schillerstrasse 1, D-07745 Jena, Germany. J. Ferre-Borrull is now with the Applied Physics and Optics Department, University of Barcelona, Diagonal 647, E-08028 Barcelona, Spain. J. M. Bennett (jbennett@ridgenet.net) is with the Physics Division, Naval Air Warfare Center, China Lake, California 93555.

Received 11 April 2001; revised manuscript received 31 August 2001.

0003-6935/02/010154-18\$15.00/0

(C) 2002 Optical Society of America identical samples were sent to various laboratories, and measurements were made on a specific type of instrument by use of a prescribed protocol.

When different types of measurements made on the same samples are converted to a common quantity, for example, rms roughness, and compared, the results are generally different because the spatialfrequency bandwidth limits of the instruments are different. It is now possible to calculate the power spectral density (PSD) function for the surface of a material ${ }^{8,9}$ from the experimental measurements and correct for the spatial-frequency bandwidth limit differences of the individual instruments. The PSD represents the spatial-frequency spectrum of the surface roughness measured in inverse-length units. Roughness values are obtained from the area under a band-limited part of the PSD function. The onedimensional (1-D) PSD is the square of the Fourier transform of a linear surface profile, whereas the two-dimensional (2-D) PSD is the so-called surface factor of the ARS function ${ }^{1}$ for surfaces whose rms roughness is small compared to the wavelength of the illuminating light. For isotropic surfaces, there is a relation between the 1-D and the 2-D PSDs. ${ }^{10-12}$

For applications involving surface roughness and scattering in the visible spectral region, the impor- 
tant part of the PSDs is for the intermediate spatialfrequency values between $10^{-3}$ and $5 \mu \mathrm{m}^{-1}$, almost 4 orders of magnitude. (In this paper we define the spatial frequency as the reciprocal of the spatial wavelength without a factor of $2 \pi$.) Lower spatial frequencies represent the shape or optical figure (deviation of the surface from a desired shape), and higher spatial frequencies represent the roughness of the finest-grained optical coatings. These spatial frequencies do not produce scattering in the visible spectral region but are important for vacuum ultraviolet and x-ray applications. For most isotropic surfaces, the PSD decreases from low to high spatial frequencies. The manner in which it decreases depends on the process by which the surface is made.

The PSD specification of surface structure is becoming more widely used, but most comparisons still use rms roughness as the basis for the comparison, and the spatial-frequency bandwidth limits of the different measurement instruments are not the same. In one case in which PSDs were compared, ${ }^{13,14}$ they were calculated by different algorithms for the different measurement techniques, and some of the multiplication factors were different; therefore a single master curve could not be obtained for a surface.

The most recent, comprehensive instrument intercomparisons made on the same (or nearly identical) substrates have been reported by Marx et al..13,14 Abe et al. ${ }^{15}$ Duparré and Jakobs, ${ }^{16}$ Duparré and Notni, ${ }^{17}$ and Jacobson et al. ${ }^{18}$ Marx et al. ${ }^{13,14}$ used twelve 20cm- (7.9-in.-) diameter silicon wafers with various degrees of isotropic surface roughness that they produced by grinding, lapping, partial polishing, or standard polishing. The measurement techniques included an atomic force microscope (AFM), ARS, a 1-D (linear) optical profiler and a 2-D (area) optical profiler, two mechanical profilers, and a capacitance gage. Complete rms roughness data and PSD curves were given for one ground and one partially polished sample. The rms roughness values for the ground sample varied by nearly a factor of 2 and over 400 times for the smoother partially polished sample for different measurement techniques and different spatial-frequency ranges.

Abe et al. ${ }^{15}$ used 10.16-cm- (4-in.-) diameter silicon wafers with different grades of polish: mechanical, chemical, balanced chemical and mechanical (standard wafer polish), and mechanical with a small material removal rate. The measurement techniques included an AFM; a scanning-tunneling microscope; an optical profiler; a mechanical profiler; a scanning optical microscope with differential phase contrast; and an instrument that measured light-scattering topography, light point defects, and subsurface damage over the entire wafer. No PSDs were calculated, although the range of surface spatial wavelengths was given for each method. The measurement methods were consistent in that the wafers with the two coarser grades of polish had larger roughnesses than those with the standard polish and the special mechanical polish.
Duparré and Jakobs ${ }^{16}$ used fused silica (with a normal polish and a superpolish), absorbing glass (two grades of polish), and silicon substrates, with $\mathrm{MgF}_{2}$ single-layer and $\mathrm{MgF}_{2} / \mathrm{LaF}_{3}$ two-layer coatings on the absorbing glass. An AFM, optical profiler, ARS, and total integrated scattering (TIS) were used as measurement techniques. Rms roughnesses were reported for all measurement techniques along with the appropriate surface spatial wavelengths, and PSDs were plotted for the bare and film-coated substrates using AFM data. There were no PSDs for the optical profiler or the ARS measurements. In a more recent study, Duparré and Notni ${ }^{17}$ used light scattering, an AFM, and a white-light interferometer (WLI) to measure the roughness of several bare and film-covered surfaces. PSDs were reported for these measurements.

For the comparison reported by Jacobson et al.,18 polished silicon, copper, electroless nickel, and molybdenum substrates were used. Measurement techniques included ARS, TIS, a 2-D optical profiler, and a mechanical profiler. PSDs (from ARS measurements) were plotted only for copper and molybdenum, although the surface spatial frequency limits were given for all the measurements.

The study reported in this paper is different from the previous studies because (1) dielectric, semiconductor, and metal substrates of a wide range of roughness were used; (2) all samples were measured by at least two and up to five different techniques; (3) rms roughnesses, their spatial wavelength limits, and the PSDs for several measurement techniques are reported for each sample; and (4) all but one of the PSDs are 2-D and are calculated on the basis of the same definition, so they are directly comparable. Finally, rms roughnesses are calculated from the areas under the PSD curves for the same upper- and lowersurface spatial frequency limits to directly compare measurement techniques.

\section{Samples}

Characteristics of the samples used in the study are listed in Table 1. They were made of different materials and had a wide range of roughnesses, so a variety of measurement techniques could be used. We examined the surfaces of all samples in a differential interference contrast (Nomarski) microscope ${ }^{19-21}$ before taking the measurements to determine the surface structure and to check for particulate contamination. Photographs were taken of all the nontransparent samples, and images of two surfaces are shown in Section 5 . In some cases the samples were cleaned before they were measured.

\section{Instruments}

The instruments and measurement techniques were chosen to give information about surface structure in different surface spatial wavelength regions as well as to measure surfaces of different roughness. Some instruments [AFM, mechanical profiler, WLI, and confocal laser scanning microscope (LSM)] gave surface profiles or area maps, whereas ARS and TS (see 
Table 1. Samples Used in the Characterization Measurements

\begin{tabular}{|c|c|c|c|}
\hline Sample & $\begin{array}{l}\text { Diameter } \\
(\mathrm{cm})\end{array}$ & $\begin{array}{l}\text { Thickness } \\
\text { (mm) }\end{array}$ & Surface Finish \\
\hline Fused-silica A & 2.54 & 3 & Superpolish \\
\hline Fused-silica B & 2.54 & 3 & Superpolish \\
\hline Zerodur 665 & 2.54 & 5 & Superpolish \\
\hline Zerodur 666 & 2.54 & 5 & Superpolish \\
\hline Silicon carbide & 3.81 & 3 & Superpolish \\
\hline Sapphire & 3.81 & 3 & $\begin{array}{l}\text { Standard } \\
\text { polish }\end{array}$ \\
\hline Silicon wafer 1 & 5.08 & 0.5 & Wafer polish ${ }^{a}$ \\
\hline Silicon wafer 2 & 5.08 & 0.5 & Wafer polish ${ }^{a}$ \\
\hline Silicon wafer 3 & 5.08 & 0.5 & Wafer polish ${ }^{a}$ \\
\hline Fused-silica SQ1 & 2.54 & 3 & $\begin{array}{l}\text { Standard } \\
\text { polish }\end{array}$ \\
\hline Gold A & 2.54 & 5 & Electroplated $^{b}$ \\
\hline Gold B & 2.54 & 5 & Electroplated $^{b}$ \\
\hline Gold C & 2.54 & 5 & Electroplated $^{c}$ \\
\hline Brass & 2.54 & 3 & Diamond turned $^{d}$ \\
\hline Fused-silica SQ1 & 4.1 & 5 & Coarse ground \\
\hline
\end{tabular}

${ }^{a}$ Standard chemical-mechanical polish.

${ }^{b}$ Diamond-turned aluminum substrate.

${ }^{c}$ Polished glass substrate.

${ }^{d}$ Diamond turned on center, $10-\mu \mathrm{m}$ groove spacing plus additional roughness caused by tool-sample vibration; corrosion spots on surface.

Subsection 3.F) gave statistical information about surface structure but no profiles. As mentioned above, a Nomarski microscope was used to inspect and photograph the surfaces of the samples.

\section{A. Atomic Force Microscope}

The AFM is one of the family of scanning probe microscopes that was generated by the invention of the scanning-tunneling microscope. The pioneering research was done by Young et al. ${ }^{22}$ in 1972; and the first modern instrument was built by Binnig, Rohrer, and co-workers in 1981. ${ }^{23,24}$ The AFM was proposed by Binnig et al. in $1986^{25}$ and rapidly developed into several commercial instruments. Information about the principles and operation of the AFM and other scanning probe microscopes can be found in two recent books. ${ }^{26,27}$ The instrument used for the measurements reported in this paper was a Digital Instruments Dimension $3000 \mathrm{AFM}^{28}$ operated in the Tapping Mode and with an ultrasharp silicon probe of 10 -nm radius. The instrument peak-to-valley height range was approximately $6 \mu \mathrm{m}$, and the scan area could be up to $100 \mu \mathrm{m} \times 100 \mu \mathrm{m}$. The rms noise in the vertical dimension was $<0.05 \mathrm{~nm}$, and the lateral accuracy was typically $1 \%$. The image drift between successive scans of the same area was small and could be neglected. Measurements with $512 \times 512$ data points were taken at two positions on each sample with scan areas of $1 \mu \mathrm{m} \times 1 \mu \mathrm{m}, 10 \mu \mathrm{m} \times 10 \mu \mathrm{m}$, and 50 $\mu \mathrm{m} \times 50 \mu \mathrm{m}$. No $50 \mu \mathrm{m} \times 50 \mu \mathrm{m}$ scan was possible for the coarse-ground fused-silica sample SQ1 because the surface was too rough. This instrument had been used previously for other surface measurements in the same laboratory. $16,17,29,30$

\section{B. Mechanical Profiler}

A Taylor Hobson ${ }^{31}$ Talystep mechanical profiler ${ }^{32}$ at the Naval Air Warfare Center was used for linear profile measurements. Six different positions were measured on each sample, and there were two profile lengths: $800 \mu \mathrm{m}$ (data point spacing, $0.38 \mu \mathrm{m}$; stylus speed, $31 \mu \mathrm{m} / \mathrm{s} ; 2126$ data points) and $200 \mu \mathrm{m}$ (data point spacing, $0.038 \mu \mathrm{m}$; stylus speed, 3.1 $\mu \mathrm{m} / \mathrm{s} ; 5314$ data points). A light loading of $1 \mathrm{mg}$ was used for the $0.8-\mu \mathrm{m}-(800-\mathrm{nm}-)$ radius conical diamond stylus so as to not damage the surfaces. The stylus loading was set manually, and measurements were controlled and analyzed with a PC with TransEra software surrounding the Hewlett-Packard Basic Bennett-Fellows operating program. Software was available to calculate various statistical parameters from the surface profiles. However, to maintain consistency with the other instruments, the PSD was calculated with routines at the Fraunhofer Institute. The linear variable differential transformer stylus pickup could measure only a peak-tovalley height of $\sim 25 \mu \mathrm{m}$ before it became nonlinear, so profile measurements were not made on the coarse-ground fused-silica sample SQ1.

\section{White-Light Interferometer}

White-light interferometry has recently become a wellestablished method in microscopic profilometry. ${ }^{33-35}$ The instrument used for the measurements reported here was built at the Fraunhofer Institute. Interference fringes of a surface are created by means of a microscope objective equipped with a built-in interferometer such as a Michelson or a Mirau interferometer. White light from a quartz halogen lamp is used for illumination. Because the coherence length is so short, interference fringes occur only in those areas of the sample where the optical path difference between the interferometer arms is close to zero. A piezoelectric phase shifter is used to move the sample in small steps in the $z$ direction; at each step the interference image is captured by a CCD camera. As the zero optical path difference position is approached, the interference fringe pattern changes from a constant value to a rapidly fluctuating sinusoidal signal that has a maximum value for zero optical path difference. Although commercial WLIs calculate the envelope of the interference fringe pattern and store the $z$ value that corresponds to the maximum of the envelope, the Fraunhofer instrument detects the actual $z$ position of the zero-order fringe. The advantage of this method is that the $z$ position is more precise because the fringe width is much smaller than the width of the envelope, but the disadvantage is that the algorithm may jump from the zero-order fringe to the next-neighbor fringe for some pixels. This is what happened for measurements on the diamond-turned brass sample.

The Fraunhofer instrument used sub-Nyquist sampling to reduce measurement time and wavelet filtering ${ }^{36,37}$ to improve noise sensitivity. Three different magnification objectives produced measurement areas of $140 \mu \mathrm{m} \times 140 \mu \mathrm{m}, 280 \mu \mathrm{m} \times 280 \mu \mathrm{m}$, 


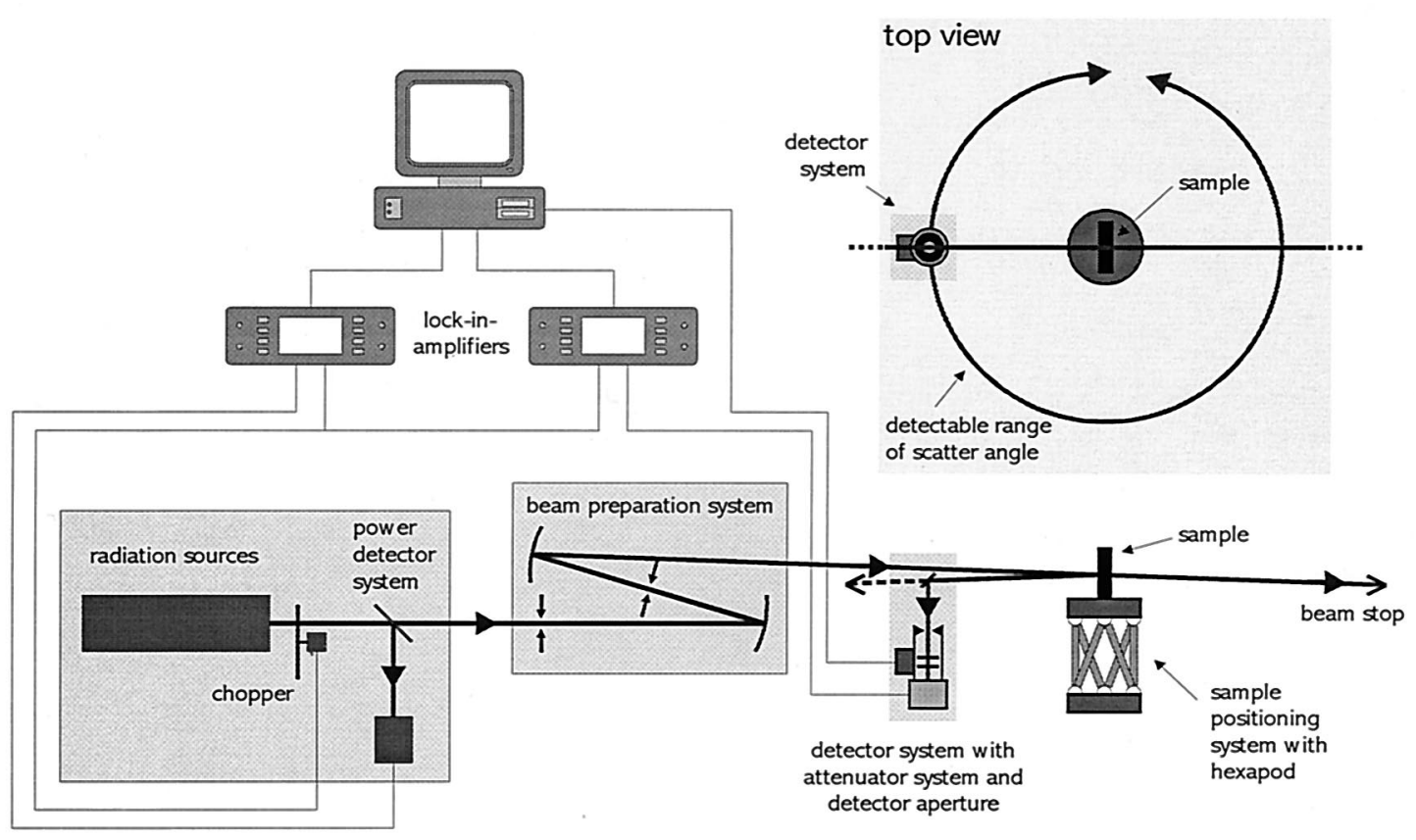

Fig. 1. Schematic diagram of the instrument to measure ARS.

and $1.1 \mathrm{~mm} \times 1.1 \mathrm{~mm}$. The vertical movement was determined separately for each sample. The maximum vertical movement was $500 \mu \mathrm{m}$ with a vertical resolution of $25 \mathrm{~nm}$ for heights between 100 and 500 $\mu \mathrm{m}$, but only the range $<100 \mu \mathrm{m}$ with a vertical resolution of $2 \mathrm{~nm}$ was used for the measurements reported in this paper. Measurements were made at three positions on each sample for all measurement areas.

\section{Confocal Laser Scanning Microscope}

Confocal laser scanning microscopy is a wellestablished technique to investigate surfaces and biological tissues. ${ }^{38-40}$ In the microscope, a laser beam is focused onto a sample with a microscope objective, and then the reflected light is imaged onto a detector. The confocal effect is achieved when a pinhole is placed at the conjugate position with respect to the focused spot on the sample. Then almost the only light is that coming from the focused plane on the sample; it passes through the conjugate pinhole in front of the detector, allowing for a precise height determination. To perform a measurement, the sample is moved in the $z$ direction by means of a linear positioner; for each $z$ position the beam is scanned over the surface by a rotating mirror scanner. We can then obtain topographical information for every point on the sample by finding the $z$ position corresponding to the maximum intensity.

The instrument at the Fraunhofer Institute was a commercial Carl Zeiss, Model LSM 510, microscope ${ }^{41}$ equipped with $\mathrm{He}-\mathrm{Ne}$ and argon-ion lasers. For these measurements, the $\mathrm{He}-\mathrm{Ne}$ laser (632.8-nm) light source was used. Heights could be measured up to $200 \mu \mathrm{m}$ with a precise galvanometric-driven positioner or up to $2 \mathrm{~cm}$ with a motor-driven posi- tioner. Three objectives gave fields of view of 130 $\mu \mathrm{m} \times 130 \mu \mathrm{m}, 260 \mu \mathrm{m} \times 260 \mu \mathrm{m}$, and $650 \mu \mathrm{m} \times 650$ $\mu \mathrm{m}$. The height resolution was better than $100 \mathrm{~nm}$. Only one sample, coarse-ground fused-silica SQ1, was measured with this technique because of its large roughness compared with the rest of the samples. Measurements were made at three positions on the sample for all measurement areas.

\section{E. Angle-Resolved Scattering}

ARS is a powerful tool to use to relate scattering properties to surface statistics with an appropriate theory. For surfaces whose roughness is small compared to the wavelength, there are numerous versions of scalar and vector scattering theories.9,42 For rougher surfaces, the theories are not as useful because more information about the optical and geometric properties of the surfaces is required. The samples studied here are in the small roughness regime, and vector scattering theory was used to obtain a 2-D PSD, as described in Section 4.

A schematic diagram of the ARS instrument at the Fraunhofer Institute, which was used for the measurements reported in this paper, is shown in Fig. 1. A more detailed description is given in Refs. 43 and 44. It had several visible and ultraviolet lasers as light sources. The sample holder was fixed on a hexapod base that allowed for full sample translation and rotation and in-plane and out-of-plane scattering measurements. The sample holder and detector were each mounted on precision goniometers with an angular resolution of $0.01^{\circ}$. The setup with a Hamamatsu side-on photomultiplier detector had a dynamic range of $10^{11}$ and could measure forward scattering and backscattering from a sample. For the measurements reported here, the light source 


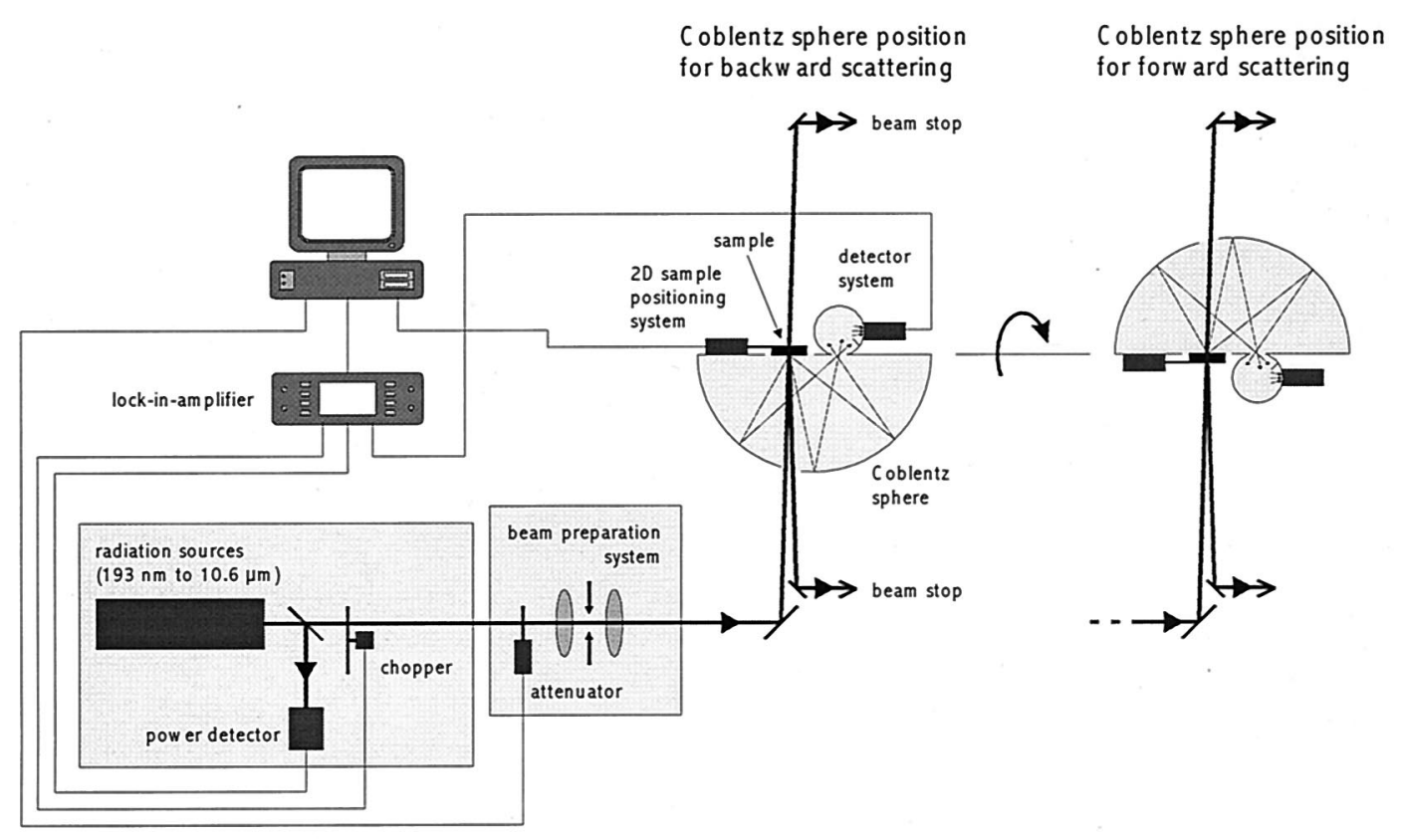

Fig. 2. Schematic diagram of the instrument to measure TS.

was a He-Ne laser beam (wavelength of $632.8 \mathrm{~nm}$ ) $\sim 2 \mathrm{~mm}$ in diameter that was normally incident on the sample. The polarization direction was perpendicular to the measurement plane. Backscattering was measured on the opaque samples and on one transparent sample, polished fused-silica SQ1.

\section{F. Total Scattering}

According to the International Organization for Standardization Final Draft International Standard (ISO/FDIS) 13696, ${ }^{45}$ TS is defined as the backscattered or forward-scattered power $P_{S}$ divided by the incident power $P_{0}$. On the other hand, TIS is defined as the backscattered power divided by the total reflected power. ${ }^{2}$ TS has the advantage over TIS in that TS is the scattering loss of the optical component and applies to transparent as well as opaque optics. However, TS and TIS can be easily converted from one to the other provided that the reflectance of the component is known. Recently, the standard procedures described in ISO/FDIS 13696 have been successfully implemented in an international roundrobin experiment. ${ }^{7}$

TS or TIS measurements can be performed with either an integrating sphere or a Coblentz sphere. ${ }^{1,7,46}$ The TS system built at the Fraunhofer Institute and shown in Fig. 2 was used for the measurements in this study. It had a Coblentz sphere and could make total backscatter or forward-scatter measurements from $193 \mathrm{~nm}$ in the deep ultraviolet through $10.6 \mu \mathrm{m}$ in the infrared by use of several lasers and an ultraviolet lamp. ${ }^{47}$ The instrument could be operated in vacuum at a wavelength of 157 $\mathrm{nm}$ and also with nitrogen as the purge gas. ${ }^{48} \mathrm{~A}$ special arrangement allowed the configuration to be easily changed from backscatter to forward-scatter operation. For the backscattering measurements reported in this paper, an unpolarized $\mathrm{He}-\mathrm{Ne}$ laser source (wavelength of $632.8 \mathrm{~nm}$ ) was used. We achieved background levels less than 0.1 parts per million at $632.8 \mathrm{~nm}$ without needing $\mathrm{He}$ gas flow or operation in vacuum. The instrument was calibrated with a commercial diffusing Spectralon (Lambertian) standard. ${ }^{49}$ The Coblentz sphere collected the light scattered into the backward or forward hemispheres within an angular range from $2^{\circ}$ to $85^{\circ}$ and imaged it onto a detector unit. The angle of incidence on the sample was close to zero, and the specularly reflected beam returned through the entrance hole in the Coblentz sphere. For the measurements reported in this paper, two perpendicular scans were made in the form of a cross. Each was 10 $\mathrm{mm}$ long and had 100 data points with $0.1-\mathrm{mm}$ spacing between points. The 200 values were then used to calculate a TS value according to the procedure given in ISO/FDIS 13696.45

The surface spatial frequencies measured by the TS system with a He-Ne laser were in the range from 0.055 to $1.57 \mu \mathrm{m}^{-1}$ (scattering angles from $2^{\circ}$ to $85^{\circ}$ ), corresponding to surface spatial wavelengths between 18 and $0.64 \mu \mathrm{m}$. Because light from all scattering angles was collected and measured as one detector signal, it was not possible to calculate a PSD. However, an effective rms roughness value could be calculated as described at the end of Section 4. The spatial frequency range for the TS measurements nearly coincided with one of the bands used to compare rms roughnesses that were measured with other instruments, so the rms roughness values calculated from the TS measurements could be included (see Table 5). 


\section{Calculation of the Power Spectral Density Function and the rms Roughness}

All topographic images of surfaces in this study were in the form of digitized data of surface heights, either as a 1-D profile in the form of $h(x)$ where $x$ is the coordinate on the surface $(0<x<L), L$ is the profile length, and $h$ is the surface height measured relative to the mean surface level; or as a 2-D array in the form of $h(x, y)$ where $x$ and $y$ are the coordinates on the surface. The area was in the form of a square that was restricted to the interval $0<x, y<L$, where $L$ is the maximum dimension and $h(x, y)$ is measured relative to the mean surface plane. The $h(x)$ and $h(x, y)$ height data were obtained from the raw height data after we corrected for offset, tilt, and curvature. The offset correction was obtained when we shifted the height of the origin so that the resulting average of all height data in a set was zero. The tilt correction eliminated possible sample inclination with respect to the mean surface plane. Curvature in the measurements could appear when the three displacement degrees of freedom of the scanning probe in an instrument such as an AFM were not completely independent. For example, curvature was observed in AFM measurements of relatively large areas (of the order of several tens of micrometers) because of the action of the piezoelectric scanner that moved the probe. We made the corrections by fitting the measured data to a polynomial by a least-squares routine and then subtracting the resulting polynomial from the measurement data. The constant term of the polynomial corresponded to the offset correction, the linear term corresponded to the tilt, and the quadratic and cubic terms corrected for the curvature.

The PSD function is customarily defined in its limiting integral form for continuous data sets $a^{8,9,50}$

$$
\begin{aligned}
\operatorname{PSD}\left(f_{x}, f_{y}\right)= & \lim _{L \rightarrow \infty} \frac{1}{L^{2}} \mid \int_{-L / 2}^{L / 2} \int_{-L / 2}^{L / 2} h(x, y) \\
& \times\left.\exp \left[-2 \pi i\left(f_{x} x+f_{y} y\right)\right] \mathrm{d} x \mathrm{~d} y\right|^{2},
\end{aligned}
$$

where the surface topography data are $h(x, y)$ and the PSD variables $f_{x}$ and $f_{y}$ are the spatial frequencies of the surface roughness and are related to the lateral dimensions of the surface features. According to Eq. (1), the PSD gives information about the relative contributions of all the possible surface spatial frequencies for an ideal measurement of an infinite surface in the limiting case from 0 frequency (an infinite surface area) to an infinite frequency (infinitely small structures).

As was noted above, the measurements in this paper are all digitized data sets, either arrays representing topography (heights) over a surface area or profiles giving surface heights along a line on the surface. In all cases the heights were measured relative to a mean surface level that was determined in the measurement area. The PSD for digitized data in one dimension (one of the Cartesian coordinates or the radial vector in polar coordinates) can be written $\mathrm{as}^{8}$

$$
\begin{aligned}
\operatorname{PSD}\left(f_{x}\right)_{N}(m)= & \mid\left(\frac{\tau_{0}}{N}\right) \sum_{n=0}^{N-1} h(x)_{n} \\
& \times\left.\exp (-i 2 \pi m n / N)\right|^{2} K(m),
\end{aligned}
$$

where $-N / 2 \leq m \leq(N / 2)-1$. Equation (2) gives an expression for the $m$ th term in the PSD calculated from a profile of $N$ points. There are now discrete values of $f_{x}=m / L$, where $L$ is the measurement length and $x$ in the function $h(x)_{n}$ takes on discrete values: $x=(L / N) n$. Also, $\tau_{0}$ is the spacing between data points in the profile, $h(x)_{n}$ are the height values of the profile data points, and $K(m)$ is a bookkeeping factor that equals 1 except that $K( \pm N / 2)=$ $1 / 2$ at the ends of the power spectrum. ${ }^{51}$ Sometimes a data window is inserted in the summation to condition the random profile data and eliminate spurious effects caused by nonzero terms at the end points of the profile data set.

With one exception, all samples used in this study were isotropic, and consequently the $\operatorname{PSD}\left(f_{x}, f_{y}\right)$ function had polar symmetry. For these surfaces, we used a simplified 2-D isotropic form of the PSD obtained by first changing from Cartesian coordinates to polar coordinates:

$$
\begin{aligned}
& f=\left(f_{x}^{2}+f_{y}^{2}\right)^{1 / 2}, \\
& \theta=\tan ^{-1}\left(\frac{f_{y}}{f_{x}}\right) .
\end{aligned}
$$

Then we averaged the resulting $\operatorname{PSD}(f, \theta)$ over the azimuthal angle to yield the 2-D isotropic PSD:

$$
\operatorname{PSD}_{2-\mathrm{D}}(f)=\frac{1}{2 \pi} \int_{0}^{2 \pi} \operatorname{PSD}(f, \theta) \mathrm{d} \theta .
$$

The averaging had a further advantage. In general, the measured PSD is not completely symmetric because of measurement errors and also because the section of surface being measured might not be a good statistical representation of the whole surface. However, because we have the additional knowledge that the surface is actually isotropic, the averaging over all angles helps to reduce the measurement errors.

Each instrument that measured a surface profile or area topography included a certain range of surface spatial frequencies. Also, we measured several places on a surface using the same conditions. In addition, different profile lengths or areas could be chosen for measurements with the same instrument. All the different PSDs could then be combined provided that two conditions are fulfilled: (1) The spatial frequency ranges corresponding to the different measurements should at least partially overlap. This condition is easily met by selection of appropriate image sizes and sampling distances. (2) In the overlapping regions, the different PSD functions should not differ significantly. To meet this condi- 
tion, it is necessary that the different measurements be correctly calibrated. If this condition is not met, it indicates that the measurements are not correct and should be repeated.

The PSD for the combined measurements is another function whose value at a given frequency $f$ is the weighted geometric mean of all the PSDs that are defined at this frequency:

$$
\operatorname{PSD}_{\text {combined }}(f)=\left[\prod_{i=1}^{M} \operatorname{PSD}_{i}(f)^{w_{i}(f)}\right]^{1 / \sum_{i=1}^{M} w_{i}(f)},
$$

where $\operatorname{PSD}_{i}(f)$ is the PSD for measurement $i, M$ is the number of PSD functions overlapping at the particular frequency $f$, and $w_{i}(f)$ is a special weighting function that decreases at the high and low spatialfrequency ends of each PSD function. ${ }^{52}$ It is better to use Eq. (5) than a simple arithmetic average that tends to favor the largest values of the PSD when those values spread over 1 order of magnitude. We obtained the PSDs presented in this paper by applying this combination relation to the PSDs obtained with the different scan lengths or areas using the same measuring instrument on the same sample. Thus we calculated master curves for each technique. We deliberately did not stitch these curves together so as to make one global master curve for each sample for two reasons. First, the additional curves would have covered the other curves, obscuring that data and not providing any new information; and, second, our purpose in this paper is to describe measurement methods and not sample properties.

For profile measurements made with the Talystep mechanical profiler, we obtained a 1-D PSD by applying Eq. (2). To be able to compare this PSD with those obtained with the 2-D measurement systems for a given surface, a conversion from the 1-D PSD to the corresponding 2-D isotropic form is needed. Relations exist for such a conversion. ${ }^{10}$ However, the equations are sensitive to the noise in the measurements and thus cannot be used for our data. To solve this problem, we developed a simpler conversion based on the relation between the rms roughness $\sigma$ and the PSD function for the 1-D and the 2-D isotropic cases:

$$
\begin{aligned}
\sigma_{\text {rms }, 1-\mathrm{D}}^{2} & =\int_{f_{\min }}^{f_{\max }} \operatorname{PSD}_{1-\mathrm{D}}(f) \mathrm{d} f, \\
\sigma_{\mathrm{rms}, 2-\mathrm{D}}{ }^{2} & =2 \pi \int_{f_{\min }}^{f_{\max }} \operatorname{PSD}_{2-\mathrm{D}}(f) f \mathrm{~d} f,
\end{aligned}
$$

where $\left(f_{\min }, f_{\max }\right)$ is the spatial frequency interval in which the PSD is defined. If we let $f_{\max }$ vary freely and call it $f^{\prime}$ and use the same $f_{\text {min }}$ for both integrals, then $\sigma_{\mathrm{rms}, 1-\mathrm{D}}\left(f^{\prime}\right)$ and $\sigma_{\mathrm{rms}, 2-\mathrm{D}}\left(f^{\prime}\right)$ are two functions of the spatial frequency. Because the rms roughness is a characteristic value of the surface, it is independent of the way it has been calculated. Consequently, the two functions should be equal as well as their deriv- atives. Following this assumption, we can then write

$$
\operatorname{PSD}_{2-\mathrm{D}}(f)=\frac{\operatorname{PSD}_{1-\mathrm{D}}(f)}{2 \pi f},
$$

which is the form of 2-D PSD that we use in Figs. 18-25 below to represent the Talystep profiler results.

Finally, ARS measurements on isotropic samples are directly related to the 2-D isotropic PSD through the common expression that can be found in the literature:9,53-56

$$
\begin{aligned}
\operatorname{ARS}\left(\theta_{s}, \phi_{s}\right)= & \frac{1}{P_{i}} \frac{\mathrm{d} P}{\mathrm{~d} \Omega}=\left(\frac{16 \pi^{2}}{\lambda^{4}}\right) \cos \theta_{i} \cos ^{2} \theta_{s} \\
& \times Q\left(\theta_{s}, \phi_{s}\right) \mathrm{PSD}_{2-\mathrm{D}}\left(f_{x}, f_{y}\right),
\end{aligned}
$$

where $\theta_{i}$ is the incident polar angle; $\theta_{s}$ and $\phi_{s}$ are the polar and azimuthal scattering angles, respectively; $P_{i}$ is the incident light intensity; and $\mathrm{d} P / \mathrm{d} \Omega$ is the light intensity scattered into a small solid angle $d \Omega$. The optical factor $Q$ depends on the incident and scattering angles, the complex refractive index of the surface material, and the state of polarization of the incident and scattered light.

One sample in the set, the brass sample, was not isotropic. It was diamond turned on center so the surface topography consisted of concentric grooves. The six Talystep profiles were all made perpendicular to the grooves. For the AFM and WLI measurements, the $x$ direction of the Cartesian coordinate system was rotated to be perpendicular to the grooves, and the $x$-direction scan lines were placed sequentially in a simulated 1-D measurement. The 1-D PSD was then calculated from all these data.

One of our main purposes in this paper is to compare roughness measurements made with different instruments in the same spatial frequency range. For this calculation we used Eqs. (6) to calculate the PSDs. We performed the integration numerically using the Romberg algorithm. ${ }^{57}$ This algorithm requires that the function being integrated be evaluated at any point in the integration domain. However, the PSD functions resulting from our measurements were digitized functions because the measurements were always made at a discrete set of points. Consequently, we used a procedure to interpolate the data for those points where the PSD was not digitized. The procedure we chose was to find the PSD at a spatial frequency $f$ that is between two sampling frequencies $f_{A}$ and $f_{B}\left(f_{A}<f<f_{B}\right)$ of the experimental PSD. We drew a straight-line segment between the points $\left[f_{A}, \operatorname{PSD}\left(f_{A}\right)\right]$ and $\left[f_{B}\right.$, $\left.\operatorname{PSD}\left(f_{B}\right)\right]$ on the log-log scale graph and estimated 


\begin{tabular}{|c|c|c|c|c|c|}
\hline \multirow[b]{2}{*}{ Sample } & \multicolumn{3}{|c|}{ Atomic Force Microscope ${ }^{a}$} & \multicolumn{2}{|c|}{$\begin{array}{c}\text { Talystep Mechanical } \\
\text { Profiler }^{b}\end{array}$} \\
\hline & $1 \mu \mathrm{m} \times 1 \mu \mathrm{m}$ & $10 \mu \mathrm{m} \times 10 \mu \mathrm{m}$ & $50 \mu \mathrm{m} \times 50 \mu \mathrm{m}$ & $200 \mu \mathrm{m}$ & $800 \mu \mathrm{m}$ \\
\hline Fused-silica A & 0.16 & 0.32 & 0.33 & 0.08 & 0.10 \\
\hline Fused-silica B & 0.16 & 0.24 & 0.40 & 0.08 & 0.10 \\
\hline Zerodur 665 & 0.23 & 0.35 & 0.43 & 0.08 & 0.09 \\
\hline Zerodur 666 & 0.44 & 0.45 & 0.41 & 0.07 & 0.10 \\
\hline Silicon carbide & 0.22 & 0.44 & 0.94 & 0.13 & 0.15 \\
\hline Sapphire & 0.19 & 0.21 & 0.23 & 0.22 & 0.36 \\
\hline Silicon wafer 1 & 0.15 & 0.28 & 0.35 & 0.32 & 0.59 \\
\hline Silicon wafer 2 & 0.14 & 0.39 & 0.39 & 0.34 & 0.65 \\
\hline Silicon wafer 3 & 0.22 & 0.37 & 0.48 & 0.31 & 0.52 \\
\hline Fused-silica SQ1 ${ }^{c}$ & 0.30 & 0.60 & 0.67 & 0.71 & 0.86 \\
\hline Gold A & 4.27 & 6.46 & 5.35 & 6.13 & 7.18 \\
\hline Gold B & 4.38 & 5.75 & 4.77 & 4.50 & 4.42 \\
\hline Gold C & 4.13 & 7.45 & 6.39 & 4.97 & 4.50 \\
\hline Brass & 5.98 & 88.1 & 93.0 & 122 & 111 \\
\hline Fused-silica SQ1 ${ }^{d}$ & 9.17 & 399 & $\longleftarrow^{e}$ & $\underline{e}^{e}$ & $\underline{e}^{e}$ \\
\hline
\end{tabular}

${ }^{a} \mathrm{AFM}$ values are the average of two readings at different places on the samples.

${ }^{b}$ Talystep values are the average of six readings at different places on the samples.

standard polish.

${ }^{d}$ Coarse ground.

${ }^{e}$ Sample was too rough to measure and was out of instrument range.

the value of the PSD at $f$ from this segment, which corresponds to applying the expression

$$
\begin{aligned}
\log [\operatorname{PSD}(f)]= & \log \left[\operatorname{PSD}\left(f_{A}\right)\right] \\
& +\frac{\log \left[\operatorname{PSD}\left(f_{B}\right)\right]-\log \left[\operatorname{PSD}\left(f_{A}\right)\right]}{\log \left(f_{B}\right)-\log \left(f_{A}\right)} \\
& \times\left[\log (f)-\log \left(f_{A}\right)\right] .
\end{aligned}
$$

The method essentially performs a linear interpolation on the log-log scale. We chose this procedure because the log-log scale is the most natural for the display of the PSD functions.

Naturally, no PSDs are achievable for TS measurements (Subsection 3.F), but a rms roughness value can be calculated as follows. First, the TS value is divided by the total reflectance of the sample, i.e., the specular reflectance of a perfectly smooth sample, to obtain a value of the TIS. Then, because all the roughnesses are small compared to the illuminating wavelength, the approximate relation between the rms roughness and the TIS is valid: ${ }^{42}$

$$
\sigma_{\mathrm{rms}}=(\lambda / 4 \pi) \sqrt{\mathrm{TIS}} .
$$

Equation (10) is the equation that was used to calculate a rms roughness value from the TS data between the surface spatial frequency bandwidths of the measurements. For the transparent sample, polished SQ1 (on which TS was measured), we used the calculation procedure that takes into account the scattering from the back surface of the sample. ${ }^{58}$

\section{Data and Results}

The rms roughnesses measured with the different profiling and mapping instruments are listed in Tables 2 and 3 . The surface spatial frequency ranges and surface spatial wavelength ranges for the measurements are given in Table 4 along with the corresponding values for the PSDs. With the exception of

\begin{tabular}{|c|c|c|c|c|c|c|}
\hline \multirow[b]{2}{*}{ Sample } & \multicolumn{3}{|c|}{ White-Light Interferometer } & \multicolumn{3}{|c|}{ Confocal Laser Scanning Microscope } \\
\hline & $\begin{array}{c}140 \mu \mathrm{m} \\
\times 140 \mu \mathrm{m}\end{array}$ & $\begin{array}{c}280 \mu \mathrm{m} \\
\times 280 \mu \mathrm{m}\end{array}$ & $\begin{array}{c}1100 \mu \mathrm{m} \\
\times 1100 \mu \mathrm{m}\end{array}$ & $\begin{array}{c}130 \mu \mathrm{m} \\
\times 130 \mu \mathrm{m}\end{array}$ & $\begin{array}{c}260 \mu \mathrm{m} \\
\times 260 \mu \mathrm{m}\end{array}$ & $\begin{array}{c}650 \mu \mathrm{m} \\
\times 650 \mu \mathrm{m}\end{array}$ \\
\hline Gold A & 4.23 & 5.58 & 6.62 & & & \\
\hline Gold B & 3.45 & 3.62 & 3.73 & & & \\
\hline Gold C & 3.38 & 2.88 & 2.86 & & & \\
\hline Brass & 206 & 227 & 207 & & & \\
\hline Fused-silica SQ1 ${ }^{a}$ & 4010 & 5820 & $-^{b}$ & 4950 & 5770 & 7810 \\
\hline
\end{tabular}
the Talystep mechanical profiler that measured profiles along lines of two different lengths, all the other

Table 3. Measured Average rms Roughnesses (nm) Obtained with a WLI and a LSM

${ }^{a}$ Coarse ground.

${ }^{b}$ Out of instrument range. 
Table 4. Surface Spatial Frequency and Surface Spatial Wavelength Ranges for the Raw Measurements (the Theoretical Ranges of the Instruments are Larger) and for the PSD Curves for all Measuring Instruments

\begin{tabular}{|c|c|c|c|c|}
\hline \multirow[b]{2}{*}{ Instrument } & \multicolumn{2}{|c|}{ Experimental Measurements } & \multicolumn{2}{|c|}{ PSD Curves } \\
\hline & $\begin{array}{l}\text { Surface Spatial } \\
\text { Frequency } \\
\left(\mu \mathrm{m}^{-1}\right)\end{array}$ & $\begin{array}{c}\text { Surface Spatial } \\
\text { Wavelength } \\
(\mu \mathrm{m})\end{array}$ & $\begin{array}{l}\text { Surface Spatial } \\
\text { Frequency } \\
\left(\mu \mathrm{m}^{-1}\right)\end{array}$ & $\begin{array}{c}\text { Surface Spatial } \\
\text { Wavelength } \\
(\mu \mathrm{m})\end{array}$ \\
\hline AFM & $0.020-256$ & 50-0.00391 & $0.05-250$ & $20-0.004$ \\
\hline Talystep & $0.00125-13.2$ & $800-0.076^{a}$ & $0.00260-5$ & $385-0.2$ \\
\hline $\mathrm{ARS}$ & $0.0138-1.57$ & $72.5-0.635$ & $0.05-1.5$ & 20-0.67 \\
\hline WLI & $0.00091-1.83$ & $1100-0.547$ & $0.0025-1.7$ & $400-0.6$ \\
\hline LSM & $0.00154-1.97$ & 650-0.507 & $0.004-2$ & $250-0.5$ \\
\hline
\end{tabular}

${ }^{a} 0.076 \mu \mathrm{m}$ is twice the digitization increment. The lateral resolution is probably $\sim 0.2 \mu \mathrm{m}$.

instruments gave topographic images with data points in a square array. No attempt was made to measure at the same locations on the surfaces with the different instruments.

The rms roughnesses measured by different instruments are difficult to compare because of the different lateral resolutions, different size measurement areas, and different data point spacings. For these reasons, we calculated the PSDs and used them to give rms roughnesses for common bandwidths. Before introducing the PSDs, we first comment on the surface conditions of the different samples.

Fused-silica A and B, Zerodur 665 and 666, silicon carbide, and sapphire had the smoothest surfaces, generally $<0.5-\mathrm{nm} \mathrm{rms}$ roughness. For some of these samples, particulate contamination was a serious problem. Even submicrometer-diameter particles could considerably increase the measured roughness. Although most of the instruments were operated in clean room or near-clean room environments, particulate contamination could not be completely avoided.

The surfaces of the two fused-silica samples were featureless. No particles, scratches, bumps, pits, or other defects could be seen. The reason that the roughnesses measured with the AFM increased with increasing image size (Table 2) is that the scanner bow could not be completely removed. Line-by-line first-order flattening was used for the $1 \mu \mathrm{m} \times 1 \mu \mathrm{m}$ and $10 \mu \mathrm{m} \times 10 \mu \mathrm{m}$ images, and third-order flattening was used for the $50 \mu \mathrm{m} \times 50 \mu \mathrm{m}$ images. When the third-order flattening was done, there was a residual waviness in the $x$ direction that had an amplitude of approximately $0.4 \mathrm{~nm}$ from the mean surface level. This waviness superposed an equivalent $\mathrm{rms}$ roughness value of approximately $0.3 \mathrm{~nm}$ on the actual rms roughness of the surface. This is the main reason for the much larger rms roughness values for the two fused-silica samples than the roughnesses measured by the Talystep. Zerodur 665 and 666 had granular structure on their surfaces. The material is a mixture of $\beta$-quartz crystallites that are $\sim 11 \mathrm{~nm}$ in diameter ${ }^{59}$ embedded in a matrix of fused silica. The crystallites are harder than the matrix and polish more slowly so they slightly protrude from the surface and produce the granular structure shown in the $10 \mu \mathrm{m} \times 10 \mu \mathrm{m}$ AFM image of Zerodur 665 in Fig. 3. The Tapping Mode AFM probe radius was nominally $10 \mathrm{~nm}$, and it partially resolved the fine lateral detail. Previously, the same surface had been profiled with an AFM having a pyramidal silicon nitride contact probe, $\sim 40$-nm radius, and the lateral structure was not resolved. ${ }^{60}$ The $800-\mathrm{nm}$ radius of the Talystep stylus also could not resolve the lateral structure. In addition to the $\beta$-quartz crystallites in the material, there were also hard, nonremovable particles on the surfaces of both samples.

The silicon carbide and sapphire samples both had scratches and hard, nonremovable particles on their surfaces, as shown in the $10 \mu \mathrm{m} \times 10 \mu \mathrm{m}$ AFM images in Figs. 4 and 5. The scratches on the sapphire were wider than those on the silicon carbide and were resolved by the Talystep stylus, but the scratches on the silicon carbide were not. The scratches on both samples had different azimuthal orientations and were nonuniformly distributed over the surfaces.

The dominant features on the three silicon wafers were particulates plus the basic surface waviness produced by the chemical-mechanical polish. Wav-

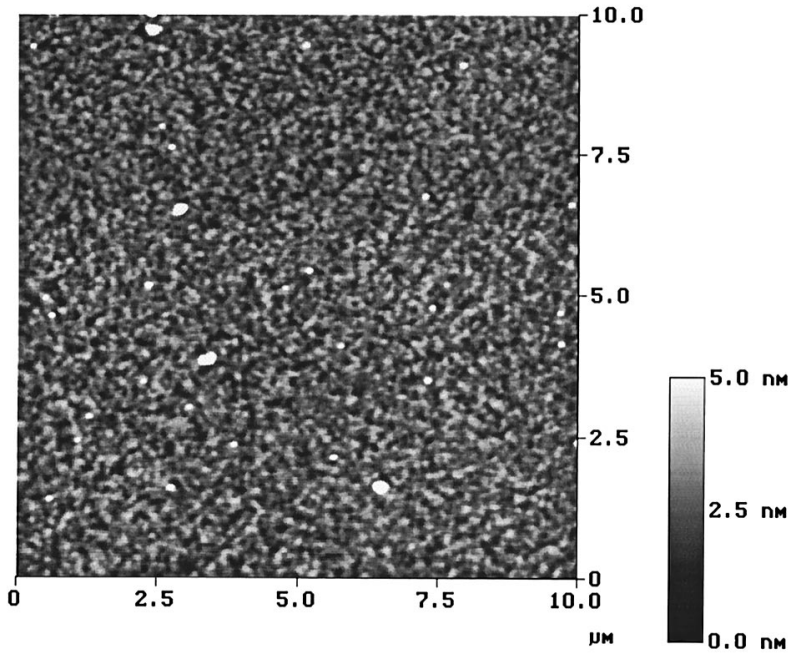

Fig. 3. $10 \mu \mathrm{m} \times 10 \mu \mathrm{m}$ AFM image of the Zerodur 665 surface. 


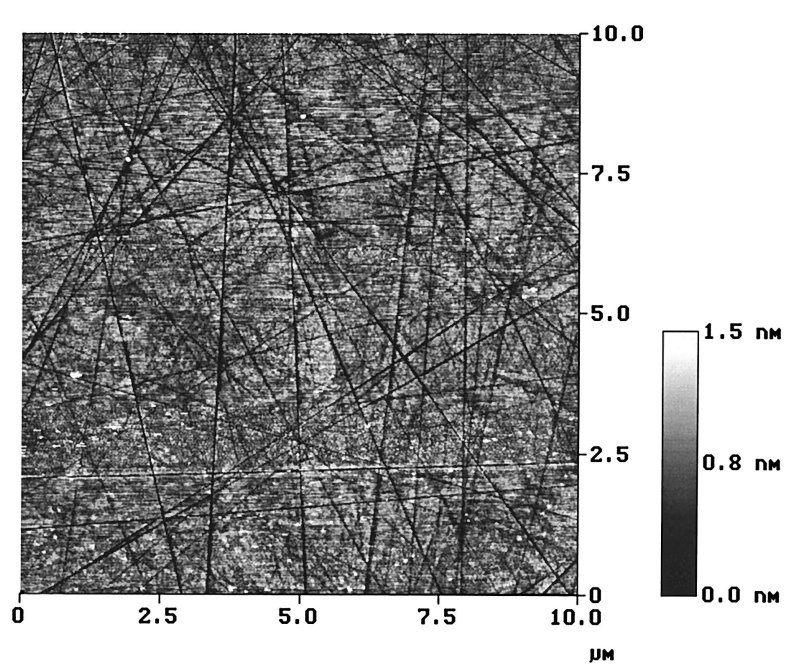

Fig. 4. $10 \mu \mathrm{m} \times 10 \mu \mathrm{m}$ AFM image of the silicon carbide surface.

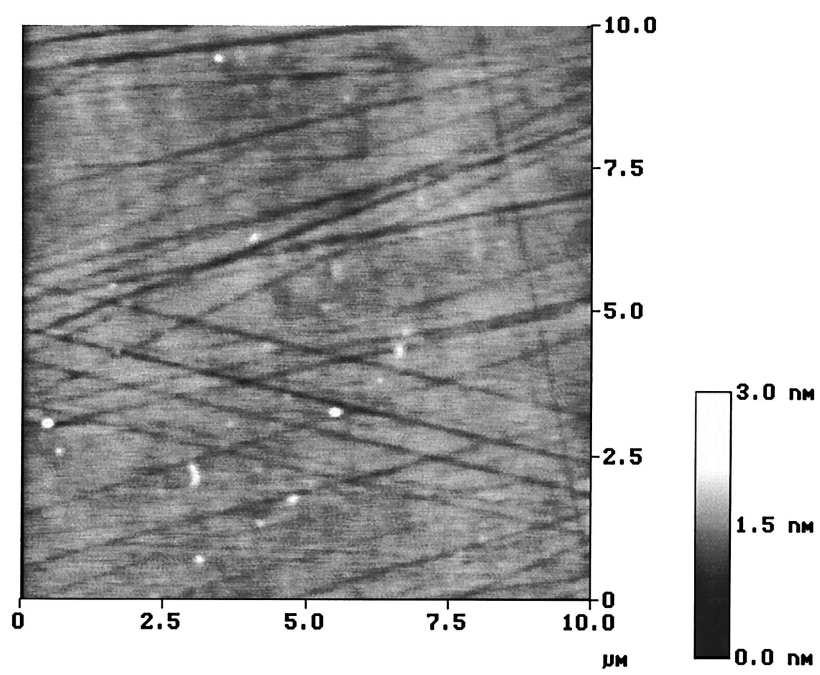

Fig. 5. $10 \mu \mathrm{m} \times 10 \mu \mathrm{m} \mathrm{AFM}$ image of the sapphire surface.

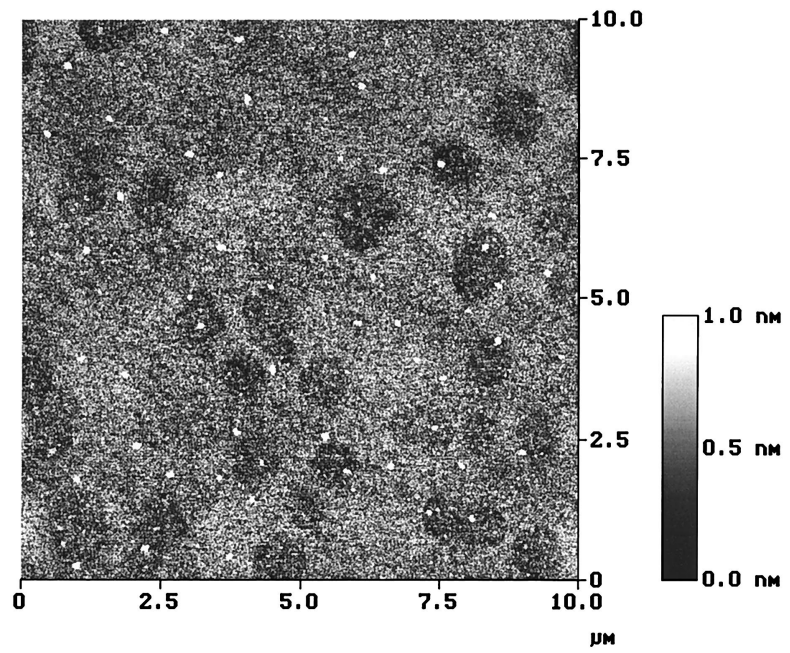

Fig. 6. $10 \mu \mathrm{m} \times 10 \mu \mathrm{m}$ AFM image of the silicon wafer 3 surface.

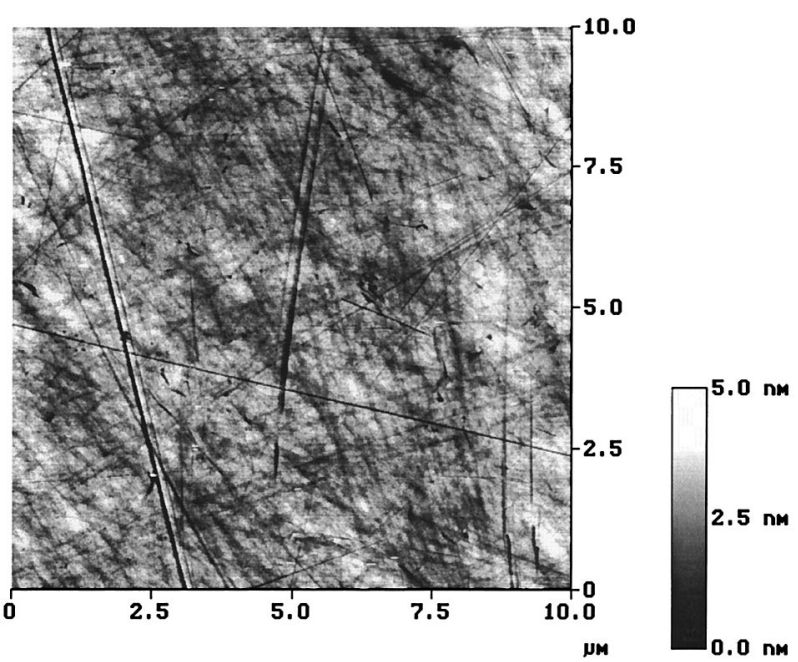

Fig. 7. $10 \mu \mathrm{m} \times 10 \mu \mathrm{m}$ AFM image of the polished fused-silica SQ1 surface.

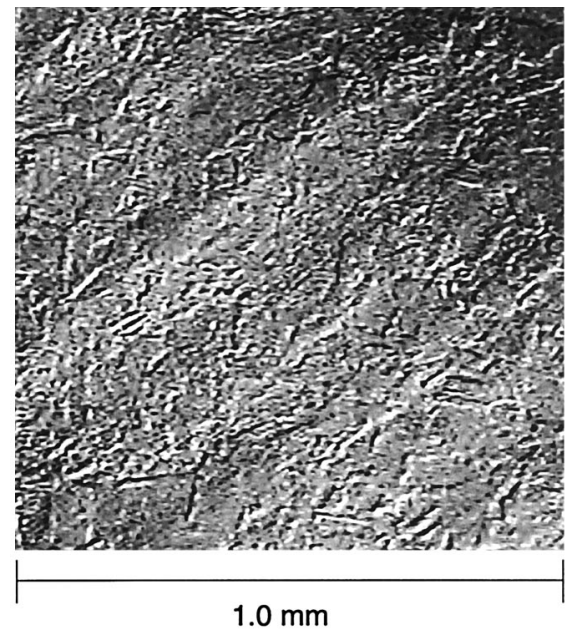

Fig. 8. Nomarski micrograph of the electroplated gold A surface.

iness shows in the $10 \mu \mathrm{m} \times 10 \mu \mathrm{m}$ AFM image of Fig. 6 as dark spots (low places on the surface), whereas particulate contamination is evidenced by the many white dots (high points) on the surface. The waviness was larger for the larger-area measurements. Both the waviness and the particles affected all types of measurements.

The surface of the polished fused-silica sample SQ1 consisted of a network of scratches of varying sizes and orientations as shown in the $10 \mu \mathrm{m} \times 10 \mu \mathrm{m}$ AFM image in Fig. 7. The scratches influenced both the topography and the scatter measurements. Because the azimuthal orientations of the scratches were random, there was no preferred sample orientation in the ARS instrument.

Gold samples A, B, and C were made by electroplating gold onto diamond-turned aluminum substrates (for gold A and B) and polished glass (for gold C). Thin layers of chromium and nickel were deposited onto the glass surface before gold $\mathrm{C}$ was electro- 


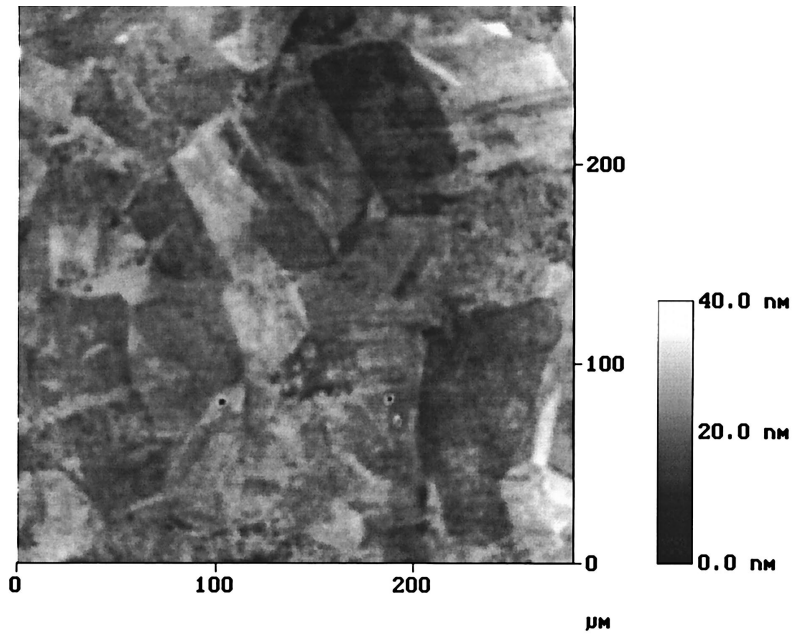

Fig. 9. $280 \mu \mathrm{m} \times 280 \mu \mathrm{m}$ WLI image of the gold A surface.

plated. The two images of gold A in Fig. $8(1 \mathrm{~mm} \times$ $1 \mathrm{~mm}$ Nomarski microscope image) and Fig. 9 (280 $\mu \mathrm{m} \times 280 \mu \mathrm{m}$ WLI image) show that the gold crystallites were quite rough and were nonuniformly distributed over the surface. Gold B and C also had nonuniform surfaces. It would be difficult to pick typical places on the surfaces of these three samples for AFM images.

The brass sample was turned on center. There were also many corrosion patches distributed over the surface, as shown in the $1 \mathrm{~mm} \times 1 \mathrm{~mm}$ Nomarski image in Fig. 10. The $280 \mu \mathrm{m} \times 280 \mu \mathrm{m}$ WLI image in Fig. 11 shows a different area without obvious corrosion patches. However, the grooves are clear.

The roughest sample was the ground fused-silica SQ1 sample. The $280 \mu \mathrm{m} \times 280 \mu \mathrm{m}$ WLI image in Fig. 12 shows that there were many different feature sizes present on the frosted-appearing surface. The smallest features look like tiny shards of broken glass. The LSM images in Figs. 13(a) and 13(b) of $260 \mu \mathrm{m} \times 260 \mu \mathrm{m}$ and $650 \mu \mathrm{m} \times 650 \mu \mathrm{m}$ areas,

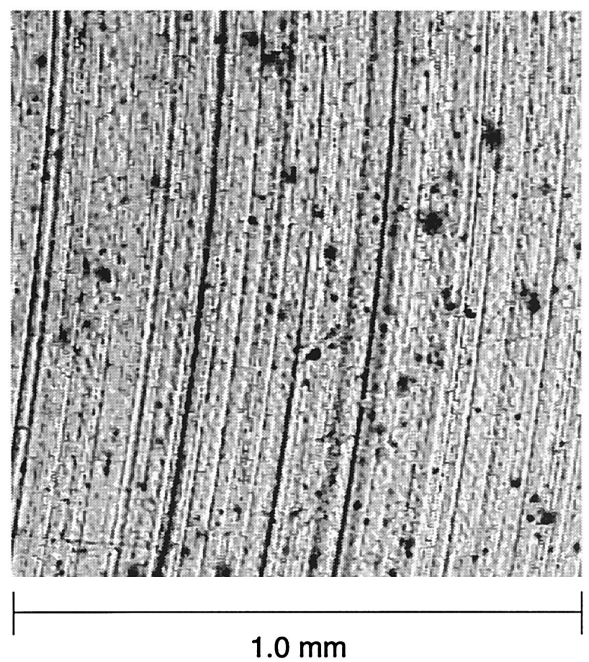

Fig. 10. Nomarski micrograph of the diamond-turned brass surface. respectively, do not show the smallest structure. The surface was too rough for the $50 \mu \mathrm{m} \times 50 \mu \mathrm{m}$ AFM image and the Talystep profiler. Because of the large lateral range of feature sizes, it is not clear whether the two smaller-area AFM topographic images are statistically significant.

Figures 14-17 show $800-\mu \mathrm{m}$ Talystep profiles of the sapphire, silicon wafer 3 , electroplated gold A, and diamond-turned brass surfaces, respectively. The vertical scales range from 2.5 to $500 \mathrm{~nm}$, whereas the $800-\mu \mathrm{m}$ horizontal scales remain constant. The rms roughness values for each profile are given in the figure captions and on the graphs. The sapphire profile (Fig. 14) shows scratches superposed on a wavy background. There was considerable closerspaced waviness on the surface of silicon wafer 3 (Fig. 15); this was also shown in Fig. 6, although the lateral dimensions in the two images are considerably different. The electroplated gold A surface (Fig. 16) was rough because of large crystallites (giving waviness to the profile) and smaller structure within the crystallites. The main structure on the brass profile (Fig. 17) is from the $10-\mu \mathrm{m}$ spaced diamond-turning grooves. The corrosion patches shown in the Nomarski image in Fig. 10 do not eliminate the grooves.

Figures 18-26 show PSDs for each of the sample types. The units for the 1-D PSDs for the brass sample are $\mathrm{nm}^{3}$ (Fig. 25) whereas all the 2-D PSDs are in units of $\mathrm{nm}^{4}$. The surface spatial frequency and surface spatial wavelength ranges shown on the PSD curves for each instrument are given in the last two columns of Table 4. With the exception of the brass sample, all surfaces were isotropic, so the 2-D (area) PSDs were azimuthally symmetric. Each PSD shown here represents a radial cut that was averaged over all azimuths. Because of the large number of data points in each Talystep profile and the relatively small number of profiles, the PSDs calculated from the Talystep data were quite

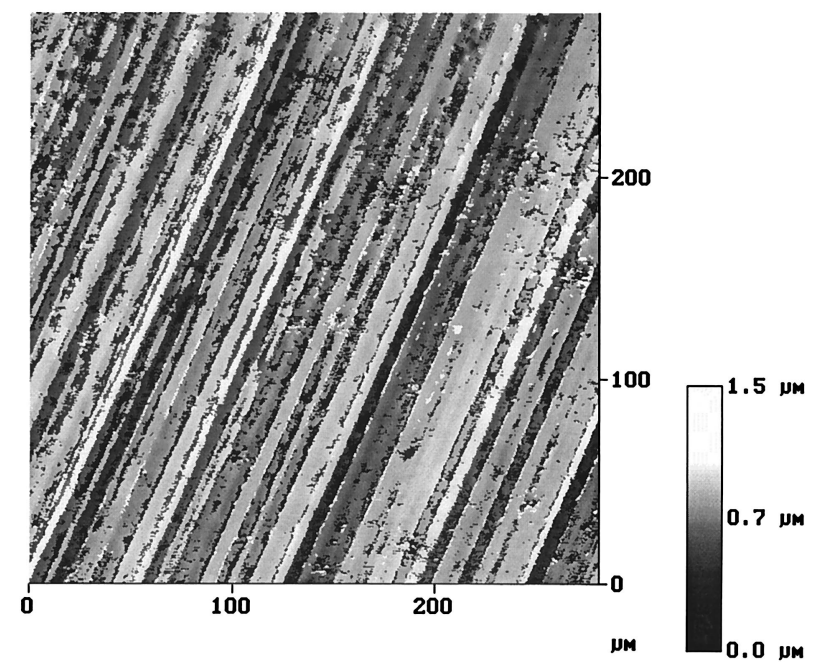

Fig. 11. $280 \mu \mathrm{m} \times 280 \mu \mathrm{m}$ WLI image of the diamond-turned brass surface. 


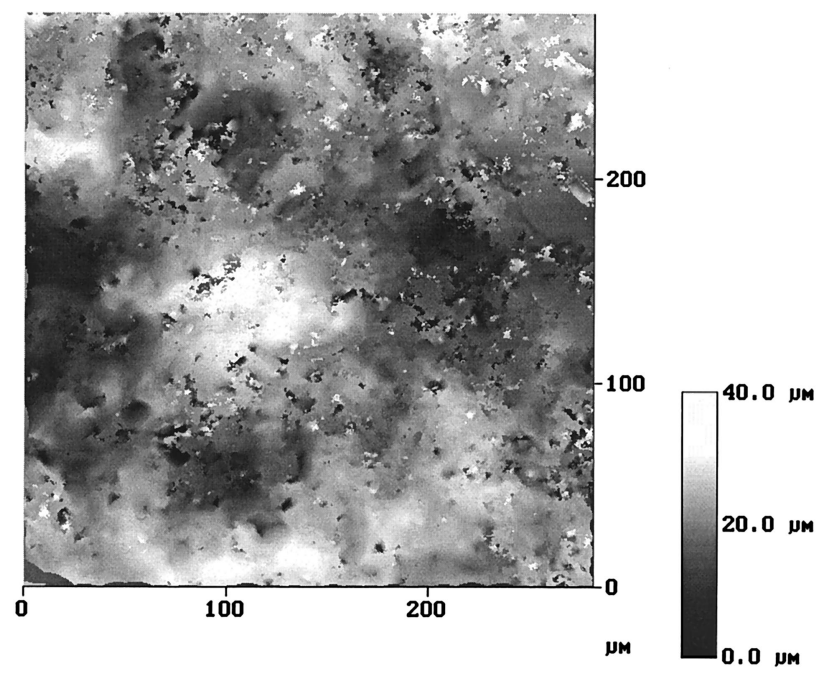

Fig. 12. $280 \mu \mathrm{m} \times 280 \mu \mathrm{m}$ WLI image of the ground fused-silica SQ1 surface.

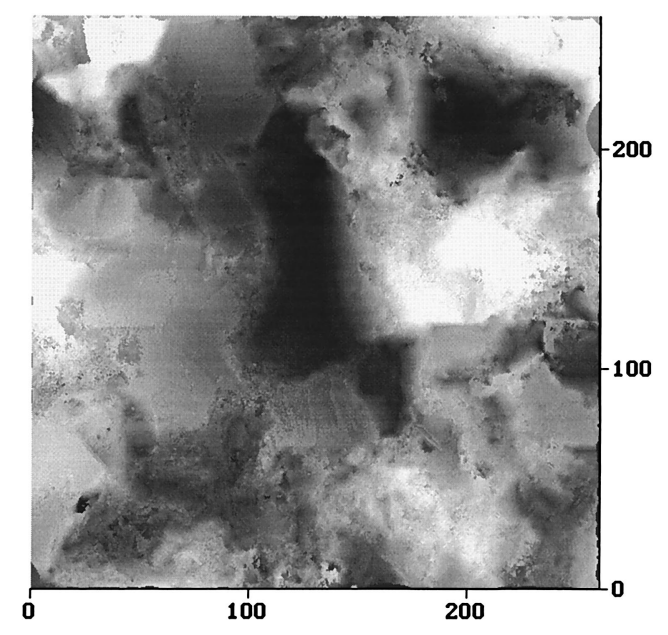

(a)
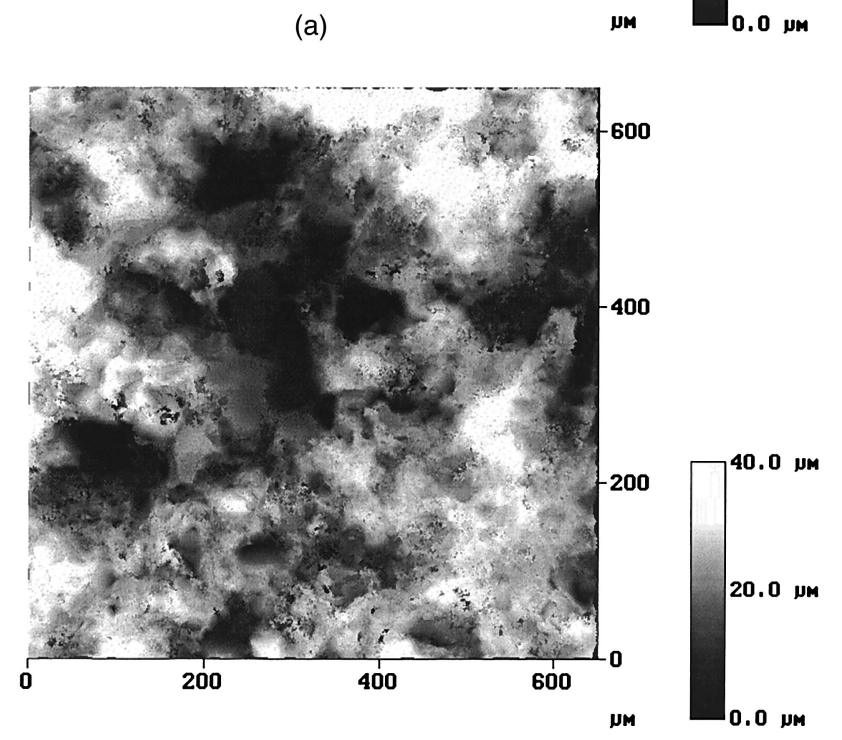

(b)

Fig. 13. LSM image of the ground fused-silica SQ1 surface: $260 \mu \mathrm{m} \times 260 \mu \mathrm{m}$ and (b) $650 \mu \mathrm{m} \times 650 \mu \mathrm{m}$ image areas.

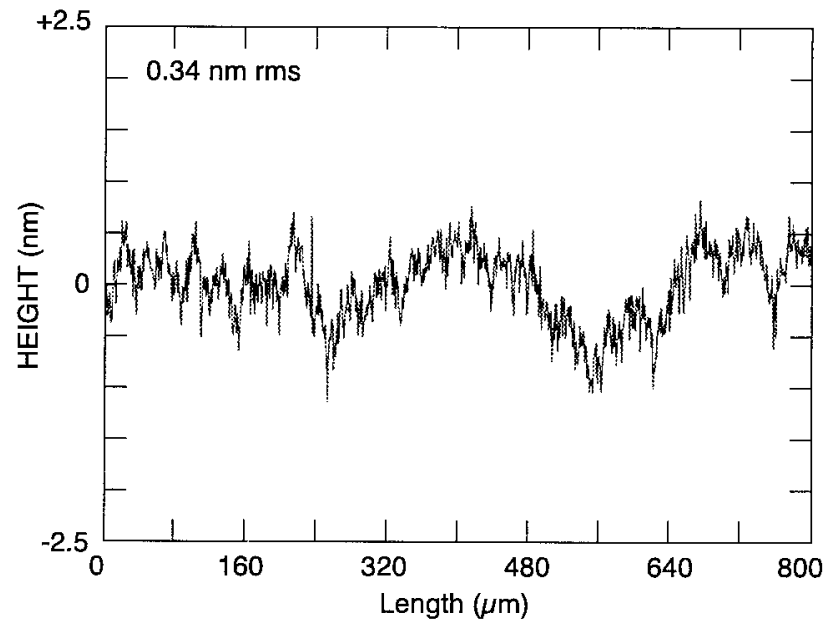

Fig. 14. $800-\mu \mathrm{m}$ Talystep profile of the sapphire surface, 0.34-nm rms roughness.

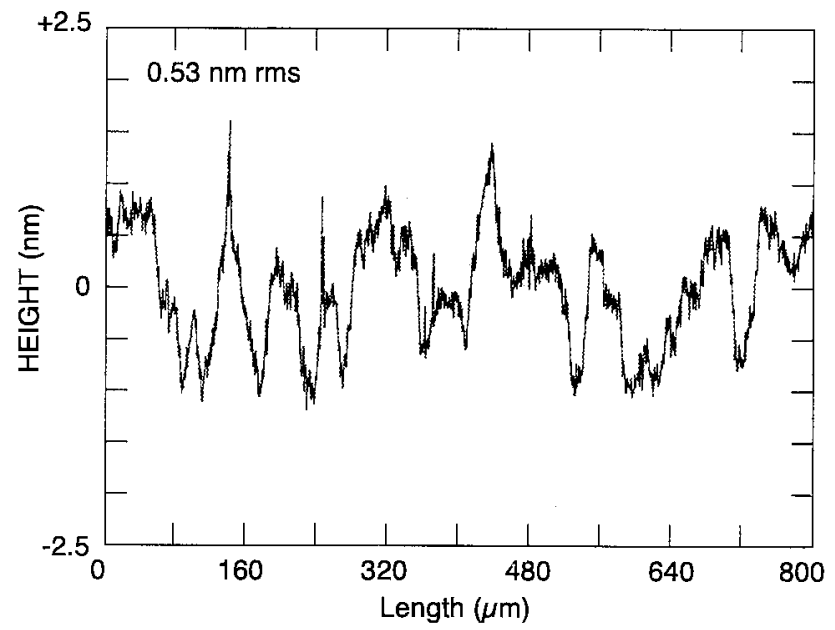

Fig. 15. $800-\mu \mathrm{m}$ Talystep profile of the silicon wafer 3 surface, $0.53-\mathrm{nm}$ rms roughness.

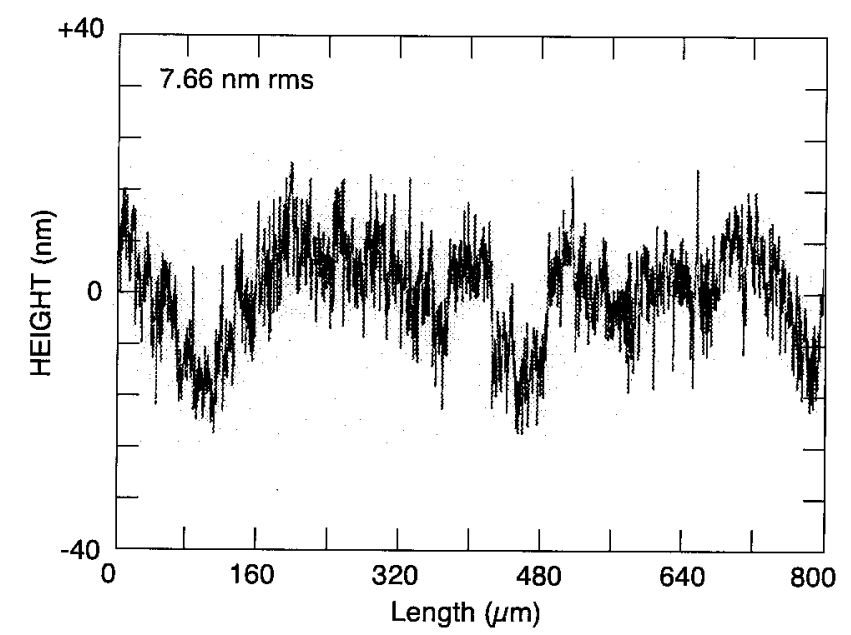

Fig. 16. $800-\mu \mathrm{m}$ Talystep profile of the electroplated gold A surface, 7.66-nm rms roughness. 


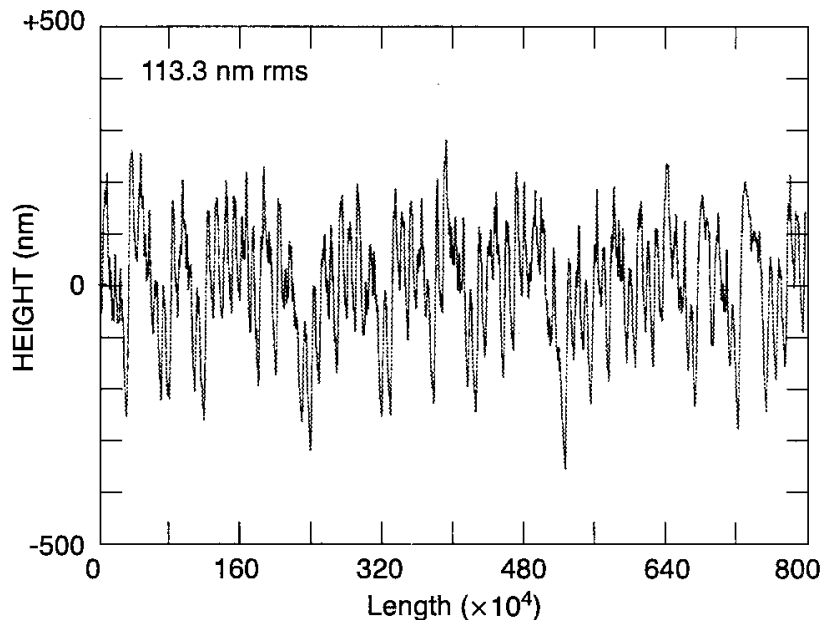

Fig. 17. 800- $\mu \mathrm{m}$ Talystep profile of the diamond-turned brass surface, 113.3-nm rms roughness.

noisy. To smooth these curves, each profile was split into several shorter lengths. PSD data calculated from each shorter profile were averaged as described in the paper by Elson and Bennett.50 This technique gave considerably smoother PSDs but at the expense of the low-frequency parts of the curves that were now missing. Fortunately the low-frequency PSDs were unnecessary for a comparison with the PSDs determined from the WLI data (Figs. 24 and 25).

\section{Discussion}

The PSDs make it possible for us to compare rms roughnesses that were made on different instruments by choosing common bandwidth regions. Four different bandwidth regions were chosen to accommodate the various instruments: band A covers the range $0.05-5 \mu \mathrm{m}^{-1}$ (AFM, Talystep), band $\mathrm{B}$ covers the range $0.05-1.5 \mu \mathrm{m}^{-1}$ (AFM, Talystep, ARS, TS, WLI), band C covers the range $0.0026-1.7 \mu \mathrm{m}^{-1}$ (Talystep, WLI), and band D covers the range 0.004$1.7 \mu^{-1}$ (WLI, LSM). The low and high spatialfrequency bandwidth limits corresponding to band A

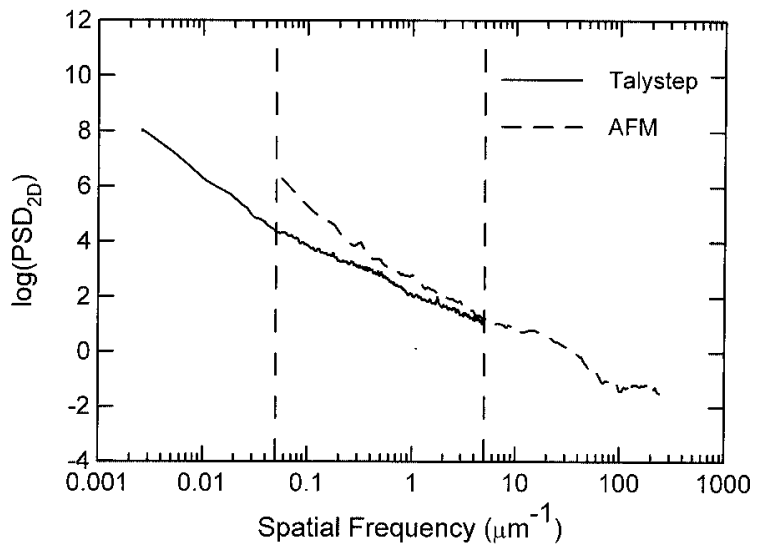

Fig. 18. PSDs for fused-silica A.

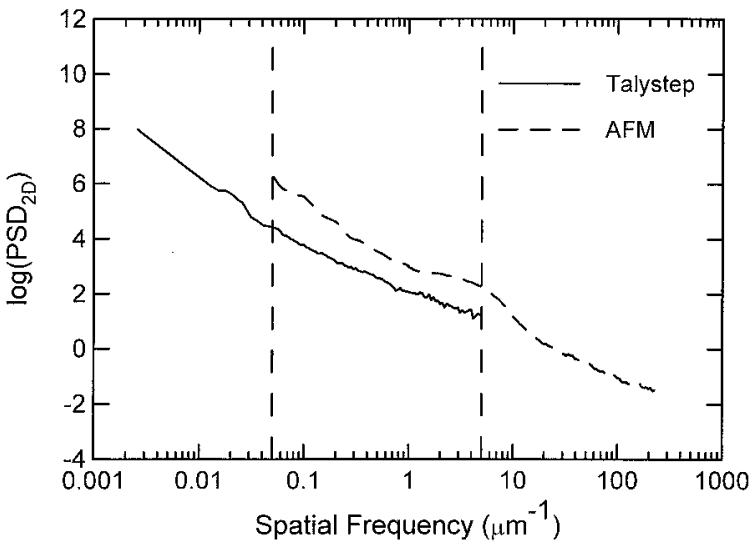

Fig. 19. PSDs for Zerodur 665.

were drawn on all PSDs in Figs. 18-26. The rms roughnesses calculated for the four different bands are given in Tables 5-7. Band A was chosen because it includes the entire region of overlap between the AFM and the Talystep measurements. Both these instruments measure surface topography but the radii of their probes are different by a factor of approximately 100 . The limits in band B are closer together than for band A, so all the roughnesses for

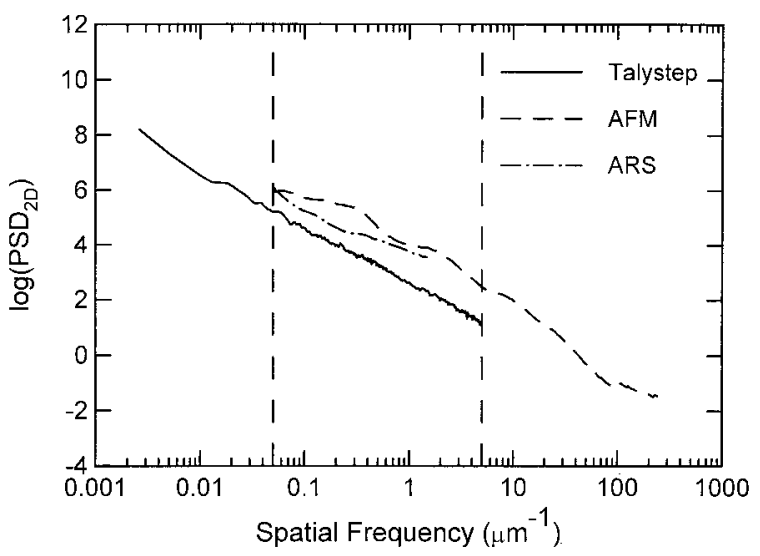

Fig. 20. PSDs for silicon carbide.

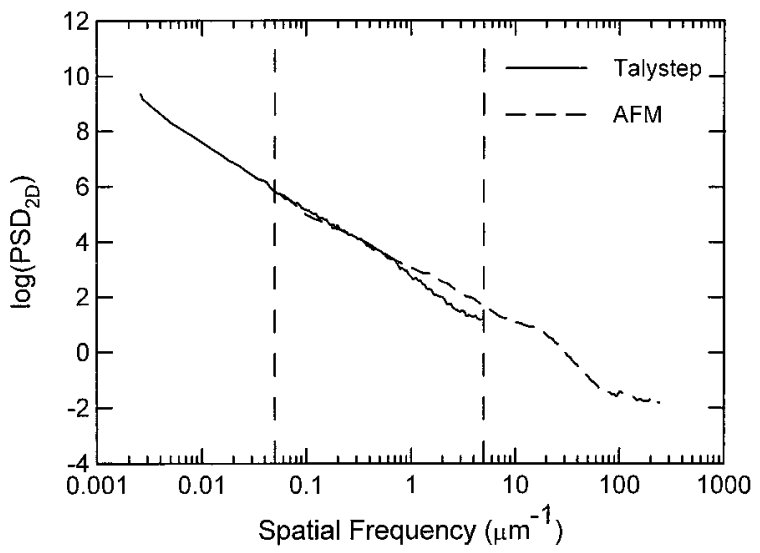

Fig. 21. PSDs for sapphire. 


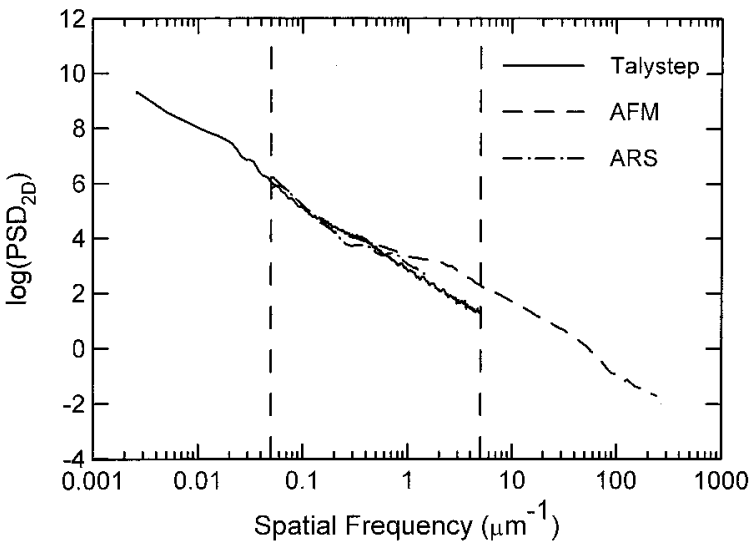

Fig. 22. PSDs for silicon wafer 3.

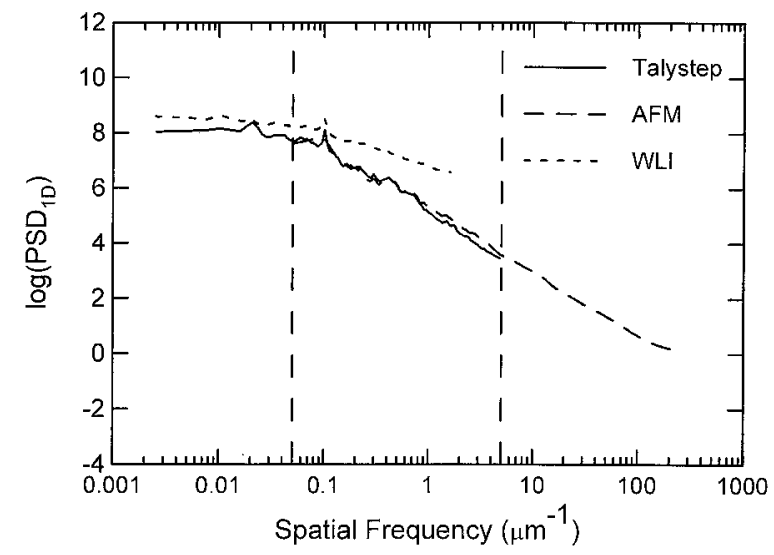

Fig. 25. PSDs for diamond-turned brass. the same instruments are smaller. TS is included in band B even though there was no PSD (see Subsection 3.F) because the bandwidth limits are close to those of band B. The low-frequency limit for band C is much lower than for bands $\mathrm{A}$ and $\mathrm{B}$, but the highfrequency limit is close to that of band $\mathrm{B}$. Thus the rms roughnesses calculated for band $\mathrm{C}$ are larger than the values for band B for the same instruments. The limits for band D are closer together than for

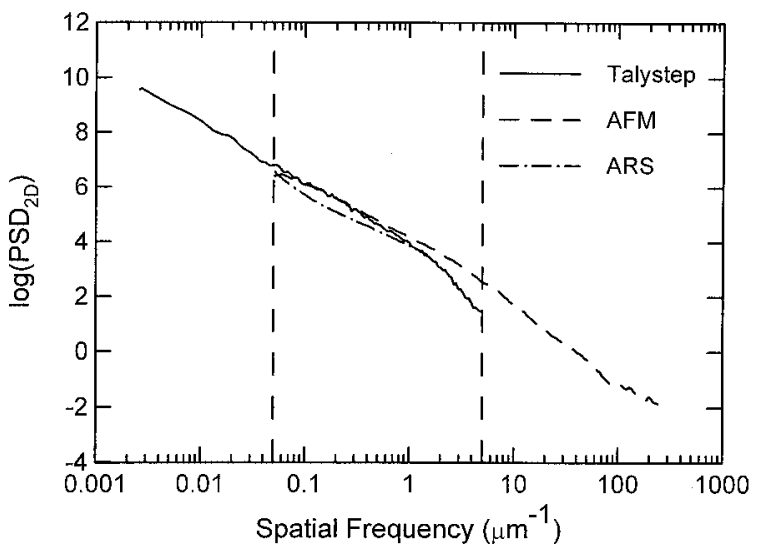

Fig. 23. PSDs for polished fused-silica SQ1.

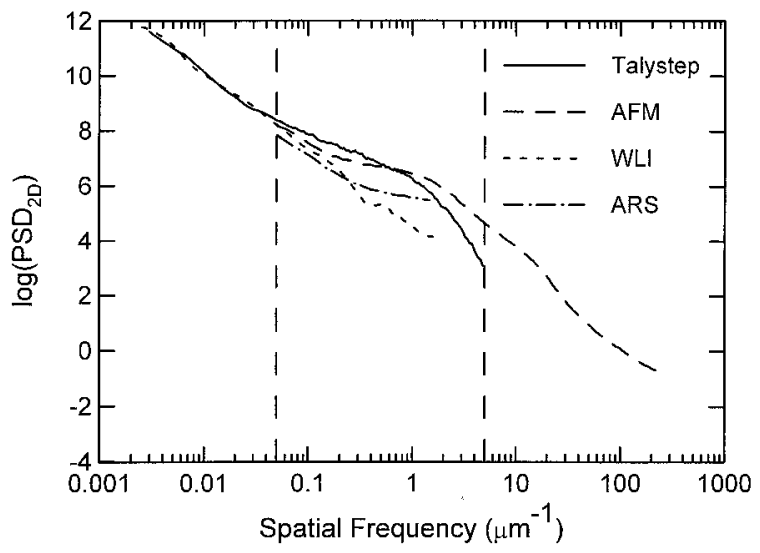

Fig. 24. PSDs for gold A. band $\mathrm{C}$, but there was only one material in band $\mathrm{D}$, coarse-ground fused silica.

When the PSD curves for the different instruments are close together, as for sapphire (Fig. 21), silicon wafer 3 (Fig. 22), polished fused-silica SQ1 (Fig. 23), and coarse-ground fused silica (Fig. 26), the rms roughness values will be in closer agreement than when the curves for the different instruments are farther apart. It is encouraging that the PSDs were close for so many samples.

To better understand the reasons for the differences when the PSDs are far apart, we now discuss each appropriate material in turn. In Fig. 18, for fused-silica A, the PSD for the AFM diverges from the Talystep PSD at the low-frequency end because the influence of the scanner bow could not be removed from the large-area AFM images. This effect is responsible for the larger AFM rms roughnesses for fused-silica A and B in both bands A and B.

The AFM PSD for Zerodur 665 (Fig. 19) is parallel to and approximately an order of magnitude higher than the Talystep PSD curve. In addition to the effect of the scanner bow mentioned above, there were numerous isolated particles on the surfaces of both Zerodur samples. On Zerodur 665, there were larger particles: $\sim 5-10 \mathrm{~nm}$ high and $\sim 50 \mathrm{~nm}$ in

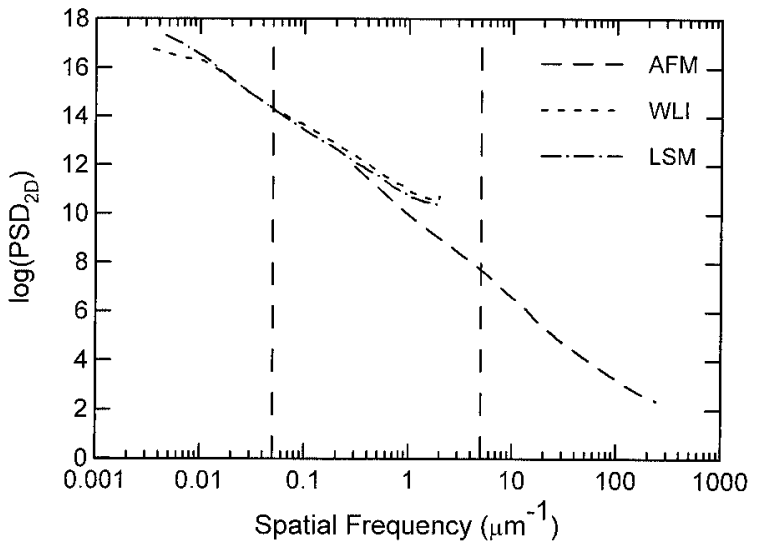

Fig. 26. PSDs for ground fused-silica SQ1. 


\begin{tabular}{|c|c|c|c|c|c|c|c|}
\hline \multirow[b]{2}{*}{ Sample } & \multicolumn{2}{|c|}{$\begin{array}{c}\text { Band A } \\
\left(0.05-5 \mu \mathrm{m}^{-1}\right)\end{array}$} & \multicolumn{5}{|c|}{$\begin{array}{c}\text { Band B } \\
\left(0.05-1.5 \mu \mathrm{m}^{-1}\right)\end{array}$} \\
\hline & $\mathrm{AFM}$ & Talystep & AFM & Talystep & ARS & $\mathrm{TS}$ & WLI \\
\hline Fused-silica A & 0.20 & 0.07 & 0.19 & 0.05 & - & - & - \\
\hline Fused-silica B & 0.14 & 0.08 & 0.14 & 0.06 & - & - & - \\
\hline Zerodur 665 & 0.26 & 0.07 & 0.20 & 0.05 & - & - & - \\
\hline Zerodur 666 & 0.26 & 0.06 & 0.17 & 0.05 & - & - & - \\
\hline Silicon carbide & 0.60 & 0.11 & 0.52 & 0.10 & 0.68 & 0.42 & - \\
\hline Sapphire & 0.20 & 0.17 & 0.17 & 0.16 & - & - & - \\
\hline Silicon wafer 1 & 0.25 & 0.16 & 0.22 & 0.15 & 0.14 & 0.14 & - \\
\hline Silicon wafer 2 & 0.29 & 0.21 & 0.26 & 0.20 & 0.16 & 0.21 & - \\
\hline Silicon wafer 3 & 0.30 & 0.17 & 0.22 & 0.16 & 0.28 & 0.25 & - \\
\hline Fused-silica SQ1 ${ }^{a}$ & 0.65 & 0.54 & 0.58 & 0.53 & 0.72 & 0.35 & - \\
\hline Gold A & 6.77 & 5.41 & 5.71 & 5.29 & 6.18 & 4.66 & 1.69 \\
\hline Gold B & 5.90 & 4.00 & 5.02 & 3.91 & 5.18 & 4.21 & 1.66 \\
\hline Gold C & 6.00 & 4.47 & 4.70 & 4.35 & 5.87 & 4.56 & 1.74 \\
\hline Brass & 72.9 & 71.2 & 72.5 & 70.5 & - & - & 184 \\
\hline
\end{tabular}

${ }^{a}$ Standard polish.

diameter with a particle density of $0.5-1 / \mu \mathrm{m}^{2}$. The particles on Zerodur 666 were smaller and much less dense: $\sim 3 \mathrm{~nm}$ high and $\sim 1.0-1.5 \mu \mathrm{m}$ in diameter with a particle density of $0.001-0.002 / \mu \mathrm{m}^{2}$. The particles interfered with the line-by-line flattening of all the AFM images, making the PSDs too large. When taking the Talystep linear profiles, we could avoid the isolated particles.

Particles were also responsible for raising the AFM PSD curve for silicon carbide (Fig. 20). On this sample, the particles were $4-8 \mathrm{~nm}$ high, $30-50 \mathrm{~nm}$ in diameter, had a density of $2-3 / \mu \mathrm{m}^{2}$, and raised the AFM PSD curve by approximately the same amount as did the particles on the Zerodur 665 sample. Particles also affected the ARS PSD curve. The $\sim 2$ $\mathrm{mm}$-diameter laser beam covered an $\sim 3-\mathrm{mm}^{2}$ area on the sample, so that the $\sim 6 \times 10^{6}$ particles in the illuminated area increased the scattering over that of

Table 6. Average rms Roughnesses (nm) Calculated from PSDs for Band C

\begin{tabular}{lcc}
\hline & \multicolumn{2}{c}{ Band C } \\
& \multicolumn{2}{c}{$\left(0.0026-1.7 \mu \mathrm{m}^{-1}\right)$} \\
\cline { 2 - 3 } Sample & Talystep & WLI \\
\hline Gold A & 7.64 & 5.92 \\
Gold B & 4.64 & 3.46 \\
Gold C & 4.80 & 2.83 \\
Brass & 102 & 232 \\
\hline
\end{tabular}

Table 7. Average rms Roughnesses (nm) Calculated from PSDs for Band D

\begin{tabular}{cll}
\hline & \multicolumn{2}{c}{ Band D } \\
& \multicolumn{2}{c}{$\left(0.004-1.7 \mu \mathrm{m}^{-1}\right)$} \\
\cline { 2 - 3 } Sample & WLI & LSM \\
\hline Fused-silica SQ1 (coarse ground) & 5140 & 6660 \\
\hline
\end{tabular}

a silicon carbide surface with no particles. The TS roughness value was similarly affected. Also, the particle coverage was not uniform over the entire surface area, and the areas measured by the different instruments were not the same. The $0.8-\mu \mathrm{m}$ diameter Talystep stylus apparently encountered many fewer particles in the places where the profiles were made, so the measured roughness values were lower than those of the other instruments.

The Talystep PSD for polished fused-silica SQ1 (Fig. 23) curls down at the highest spatial frequencies. This shape is generally caused by the instrument not resolving the highest spatial frequency surface structure, which in this case consists of fine scratches. Thus the ARS and the AFM curves are probably more representative of the true surface structure.

The surfaces of the three gold samples were considerably rougher than those of the preceding ten samples, so the influence of isolated particles was much less. The PSD curves for gold A (Fig. 24) are in the same general area but do not coincide, possibly because there was a large variation in the sizes, shapes, and heights of the large gold grains on different areas measured with the different instruments. Measuring in only two or three places on the surface would not give good ensemble statistics for a surface with this much variation, especially for the small areas sampled by the AFM. The curl down of the Talystep PSD at the highest frequencies is probably because the finest surface structure was not being resolved. The lower curve for the WLI probably also indicates incomplete resolution of the surface structure. Another factor that could explain the low PSD curve for the WLI concerns the phase change on reflection of the light at the gold surface. If the optical constants of the gold varied at the boundaries of the crystallites, this would affect the phase change on reflection of the light and make the measured values of the gold steps smaller than their actual values. In 
turn, the PSD, which is related to the square of the Fourier transform of the surface profile, would be too low. Scattered light and instrumental noise could also affect the PSD.

The brass surface consisted of circular grooves with a $10-\mu \mathrm{m}$ spacing. According to the PSD (Fig. 25), the AFM and Talystep probes were closely following the surface structure, and the small peak at a spatial frequency of $0.1 \mu^{-1}$ is for the periodicity of the grooves. The WLI curve, however, is much too high. There may be an error in the integral order of interference at discontinuities, explained as follows. The average light wavelength in the WLI was in the middle of the visible spectrum, $\sim 0.5 \mu \mathrm{m}$, but the interferometer responded to steps of half the light wavelength, or $\sim 0.25 \mu \mathrm{m}$. The peak-to-valley heights on this surface were $\sim 200-400 \mathrm{~nm}$, i.e., $0.2-$ $0.4 \mu \mathrm{m}$ (see Fig. 17 and Table 2). The slopes that occurred at the cusps of the grooves when they transitioned from one groove to the next were higher than the average slopes. In these places, the algorithms that determined the zero path difference for the individual pixels may have gotten mixed up and assigned an integral half-wave jump where there was none. If this happened, the roughness number would be much higher. Evidence that this occurred is shown in the WLI image in Fig. 11, which shows some abrupt white and dark intensity (height) differences at the boundaries of adjacent grooves. There were enough pixels in the image area to give good lateral resolution for all image sizes, so lateral resolution was not the problem. The corrosion spots on the surface raised the surface level an additional amount, so these would have further confused the assignment of the correct step heights at the groove boundaries.

The PSDs for the roughest surface, ground fusedsilica SQ1, are remarkably similar. All the curves mesh remarkably well, especially given that the AFM was sampling only two small $1 \mu \mathrm{m} \times 1 \mu \mathrm{m}$ and 10 $\mu \mathrm{m} \times 10 \mu \mathrm{m}$ areas that were probably not representative of the entire ground surface. The upward curl at the high-frequency ends of the WLI and LSM PSDs may represent noise in the instruments.

\section{Conclusions}

Surface topography and light-scattering measurements have been made on 15 samples ranging from those having smooth surfaces to others with rough ground surfaces. Six different instruments and measurement techniques were used. The rms roughnesses determined from the different measurements varied widely. These rms roughnesses were defined by the bandwidth limits of the particular instruments that were quite different. To better compare the measurements, PSD functions were calculated for each sample and measuring instrument. We then obtained roughness values by integrating the area under the different PSD curves between the same lower- and upper-surface spatial frequency band limits. This procedure removes the problem of each instrument having different upper and lower band limits on the PSD curves.

The agreement between rms roughnesses measured with the different techniques improved considerably, and the remaining differences could be explained as being caused by surface features to which the instruments responded differently. The major problems were caused by isolated particles on the surfaces of the smoother samples.

The authors thank Hanno Heise of the Fraunhofer Institute for Applied Optics and Precision Engineering for cleaning several of the samples. Part of the funding for the project was obtained from European Project Training and Mobility in Research Networking UV Coating, contract RBMFMRX CT97-0101.

\section{References and Notes}

1. J. M. Bennett and L. Mattsson, Introduction to Surface Roughness and Scattering, 2nd ed. (Optical Society of America, Washington, D.C., 1999), Chap. 3 and references therein.

2. Standard Test Method for Measuring the Effective Surface Roughness of Optical Components by Total Integrated Scattering, ASTM Doc. F1048-87 (American Society for Testing and Materials, Philadelphia, Pa., 1987).

3. J. A. Detrio and S. M. Miner, "Standardized total integrated scatter measurements of optical surfaces," Opt. Eng. 24, 419422 (1985).

4. Standard Practice for Angle Resolved Optical Scatter Measurements on Specular or Diffuse Surfaces, ASTM Doc. E1392-90 (American Society for Testing and Materials, Philadelphia, Pa., 1990).

5. T. A. Leonard and M. Pantoliano, "BRDF round robin," in Stray Light and Contamination in Optical Systems, R. P. Breault, ed., Proc. SPIE 967, 226-235 (1989).

6. T. A. Leonard, "Standardization of optical scatter measurements," in Stray Radiation in Optical Systems, R. P. Breault, ed., Proc. SPIE 1331, 188-194 (1990).

7. P. Kadkhoda, A. Müller, D. Ristau, A. Duparré, S. Gliech, H. Lauth, U. Schuhmann, N. Reng, M. Tilsch, R. Schuhmann, C. Amra, C. Deumie, C. Jolie, H. Kessler, T. Lindström, C.-G. Ribbing, and J. M. Bennett, "International round-robin experiment to test the International Organization for Standardization total-scattering draft standard," Appl. Opt. 39, 3321-3332 (2000).

8. See Ref. 1, pp. 58-64.

9. J. C. Stover, ed., Optical Scattering: Measurement and Analysis, 2nd ed., Vol. PM24 of the Press Monographs (SPIE, Bellingham, Wash., 1995).

10. E. L. Church and P. Z. Takacs, "The optimal estimation of finish parameters," in Optical Scatter: Applications, Measurement, and Theory, J. C. Stover, ed., Proc. SPIE 1530, 71-78 (1991).

11. J. M. Elson, J. M. Bennett, and J. C. Stover, "Wavelength and angular dependence of light scattering from beryllium: comparison of theory and experiment," Appl. Opt. 32, 3362-3376 (1993).

12. E. L. Church, "Fractal surface finish," Appl. Opt. 27, 15181526 (1988).

13. E. Marx, I. J. Malik, Y. E. Strausser, T. Bristow, N. Poduje, and J. C. Stover, "Round robin determination of power spectral densities of different Si wafer surfaces," in Flatness, Roughness, and Discrete Defects Characterization for Computer Disks, Wafers, and Flat Panel Displays II, J. C. Stover, ed., Proc. SPIE 3275, 26-36 (1998).

14. E. Marx, I. J. Malik, Y. E. Strausser, T. Bristow, N. Poduje, and J. C. Stover, "Power spectral densities: a multiple technique 
study of different Si wafer surfaces,” J. Vac. Sci. Technol. 20 (Jan./Feb. 2002) (to be published).

15. T. Abe, E. F. Steigmeier, W. Hagleitner, and A. J. Pidduck, "Microroughness measurements on polished silicon wafers," Jpn. J. Appl. Phys. 31, Part 1, 721-728 (1992).

16. A. Duparré and S. Jakobs, "Combination of surface characterization techniques for investigating optical thin-film components," Appl. Opt. 35, 5052-5058 (1996).

17. A. Duparré and G. Notni, "Multi-type surface and thin film characterization using light scattering, scanning-force microscopy and white light interferometry," in Optical Metrology, G. A. Al-Jumaily, ed., Vol. CR72 of SPIE Critical Reviews of Optical Science and Technology (SPIE, Bellingham, Wash., 1999), pp. 213-231.

18. R. D. Jacobson, S. R. Wilson, G. A. Al-Jumaily, J. R. McNeil, J. M. Bennett, and L. Mattsson, "Microstructure characterization by angle-resolved scatter and comparison to measurements made by other techniques," Appl. Opt. 31, 1426-1435 (1992).

19. G. Nomarski, "Microinterféromètre différentiel à ondes polarisées," J. Phys. Radium 16, 9S-13S (1955).

20. G. Nomarski and A. R. Weill, "Application à la métallographie des méthodes interférentielles à deux ondes polarisées," Rev. Metall. (Paris) 52, 121-134 (1955).

21. See Ref. 1, pp. 7-9.

22. R. Young, J. Ward, and F. Scire, "The Topografiner: an instrument for measuring surface microtopography," Rev. Sci. Instrum. 43, 999-1011 (1972).

23. G. Binnig and H. Rohrer, "Scanning tunneling microscopy," Helv. Phys. Acta 55, 726-735 (1982).

24. G. Binnig, H. Rohrer, Ch. Gerber, and E. Weibel, "Surface studies by scanning tunneling microscopy," Phys. Rev. Lett. 49, 57-61 (1982).

25. G. Binnig, C. F. Quate, and Ch. Gerber, "Atomic force microscope," Phys. Rev. Lett. 56, 930-933 (1986).

26. D. Sarid, Scanning Force Microscopy with Applications to Electric, Magnetic, and Atomic Forces (Oxford U. Press, New York, 1991).

27. S. N. Magonov and M.-H. Whangbo, Surface Analysis with STM and SFM (VCH, Weinheim, Germany, 1995).

28. Digital Instruments, a division of Veeco Process Metrology, 112 Robin Hill Road, Goleta, Calif. 93117; http://www.di.com.

29. A. Duparré, C. Ruppe, K. A. Pischow, M. Adamik, and P. B. Barna, "Atomic force microscopy on cross-sections of optical coatings: a new method," Thin Solid Films 261, 70-75 (1995).

30. C. Ruppe and A. Duparré, "Roughness analysis of optical films and substrates by atomic force microscopy," Thin Solid Films 288, 8-13 (1996).

31. Taylor Hobson Limited, P.O. Box 36, 2 New Star Road, Leicester LE4 7JQ UK (U.S. address: 2100 Golf Road, Suite 350, Rolling Meadows, Ill. 60008-4231).

32. J. M. Bennett and J. H. Dancy, "Stylus profiling instrument for measuring statistical properties of smooth optical surfaces," Appl. Opt. 20, 1785-1802 (1981).

33. M. Davidson, K. Kaufman, I. Mazor, and F. Cohen, "An application of interference microscopy to integrated circuit inspection and metrology," in Integrated Circuit Metrology, Inspection, and Process Control, K. M. Monahan, ed., Proc. SPIE 775, 233-247 (1987).

34. G. S. Kino and S. Chim, "Mirau correlation microscope," Appl. Opt. 29, 3775-3783 (1990).

35. B. S. Lee and T. C. Strand, "Profilometry with a coherence scanning microscope," Appl. Opt. 29, 3784-3788 (1990).

36. R.-J. Recknagel and G. Notni, "Measurement and analysis of microtopography using wavelet methods," in Optical Inspection and Micromeasurements II, C. Gorecki, ed., Proc. SPIE 3098, 133-143 (1997).

37. R.-J. Recknagel and G. Notni, "Analysis of white light inter- ferograms using wavelet methods," Opt. Commun. 148, 122 128 (1998).

38. C. J. R. Sheppard, "Scanning optical microscopy," in Advances in Optical and Electron Microscopy, R. Barer and V. E. Cosslett, eds. (Academic, London, 1987), Vol. 10, Chap. 1, pp. 1-98.

39. T. Wilson, "Optical aspects of confocal microscopy," in Confocal Microscopy, T. Wilson, ed. (Academic, London, 1990), Chap. 3.

40. N. J. McCormick, "Confocal scanning optical microscopy," in Surface Characterization, A User's Sourcebook, D. Brune, R. Hellborg, H. J. Whitlow, and O. Hunderi, eds. (Wiley-VCH, Weinheim, Germany, 1997), pp. 57-76.

41. Carl Zeiss Jena GmbH, Carl-Zeiss Promenade 1a, D-07745 Jena, Germany; http://www.zeiss.de.

42. See Ref. 1, pp. 28-37, 62-67.

43. J. Neubert, T. Seifert, N. Czarnetzki, and T. Weigel, "Fully automated angle resolved scatterometer," in Space Optics 1994: Space Instrumentation and Spacecraft Optics, T. M. Dewandre, J. J. Schulte-in-den-Baeumen, and E. Sein, eds., Proc. SPIE 2210, 543-552 (1994).

44. A. Duparré, S. Gliech, and J. Steinert, "Light scattering of UV-optical components," in Proceedings of the Fifth International Workshop on Laser Beam and Optics Characterization, (LBOC 5) (VDI Technologiezentrum, Düsseldorf, Germany, 2000), pp. 272-282.

45. Optics and Optical Instruments-Lasers and Laser-Related Equipment-Test Methods for Radiation Scattered by Optical Components, ISO/FDIS 13696, Technical Committee ISO/TC 172/SC9/WG6, Final Draft Standard (International Organization for Standardization, Geneva, Switzerland, 1998).

46. D. Rönnow and E. Veszelei, "Design review of an instrument for spectroscopic total integrated light scattering measurements in the visible wavelength region," Rev. Sci. Instrum. 65, 327-334 (1994).

47. A. Duparré and S. Gliech, "Quality assessment from supersmooth to rough surfaces by multiple wavelength light scattering measurement," in Scattering and Surface Roughness, Z. Gu and A. A. Maradudin, eds., Proc. SPIE 3141, 57-64 (1997).

48. S. Gliech, J. Steinert, M. Flemming, and A. Duparré, "DUV/ VUV light scattering measurement of optical components for lithography applications," in Optical Metrology Roadmap for the Semiconductor, Optical, and Data Storage Industries, G. A. Al-Jumarily, A. Duparré, and B. Singh, eds., Proc. SPIE 4099, 74-81 (2000).

49. We used 99\% reflectance Spectralon, Labsphere Inc., subsidiary of X-Rite, Inc., P.O. Box 70, North Sutton, N.H. 032600070; http://www.labsphere.com.

50. J. M. Elson and J. M. Bennett, "Calculation of the power spectral density from surface profile data," Appl. Opt. 34, 201208 (1995).

51. E. L. Church and P. Z. Takacs, "BASIC program for power spectrum estimation," Informal Rep. 490.35 (Brookhaven National Laboratory, Upton, N.Y., 1993).

52. J. Ferré-Borrull, J. Steinert, and A. Duparré, "Extending the capabilities of scanning probe microscopy for microroughness analysis in surface engineering," Surf. Interface Anal. 29, Special Issue: Papers Presented at the Fourth International Conference on the Development and Technological Application of Scanning Probe Methods 33 (2002) (to be published).

53. J. M. Elson and J. M. Bennett, "Vector scattering theory," Opt. Eng. 18, 116-124 (1979).

54. E. L. Church, H. A. Jenkinson, and J. M. Zavada, "Relationship between surface scattering and microtopographic features," Opt. Eng. 18, 125-136 (1979).

55. P. Bousquet, F. Flory, and P. Roche, "Scattering from multilayer films: theory and experiment," J. Opt. Soc. Am. 71, 1115-1123 (1981).

56. See Ref. 1, pp. $66-67$.

57. W. H. Press, B. P. Flannery, S. A. Teukolsky, and W. T. Vet- 
terling, Numerical Recipes in C (Cambridge U. Press, Cambridge, UK, 1990).

58. O. Kienzle, V. Scheuer, J. Staub, and T. Tschudi, "Design of an integrated scatter instrument for measuring scatter losses of superpolished optical surfaces, application to surface characterization of transparent fused quartz substrates," in Optical Interference Coatings, F. Abèles, ed., Proc. SPIE 2253, 1131-1142 (1994).
59. J. M. Bennett, "Surface roughness measurement," in Optical Measurement Techniques and Applications, P. K. Rastogi, ed. (Artech House, Norwood, Mass., 1997), Chap. 12, pp. 341-367.

60. J. M. Bennett, J. Jahanmir, J. C. Podlesny, T. L. Balter, and D. T. Hobbs, "Scanning force microscope as a tool for studying optical surfaces,” Appl. Opt. 34, 213-230 (1995). 